\title{
Cartel Organization, Price Discrimination, And Selection Of Transatlantic Migrants: 1899-1911
}

\author{
George Deltas \\ University of Illinois \\ 1407 W. Gregory \\ Urbana, IL 61801 \\ USA \\ deltas@illinois.edu
}

\author{
Richard Sicotte \\ University of Vermont \\ 239 Old Mill, 94 Univ. Place \\ Burlington, VT 05405 \\ USA \\ richard.sicotte@uvm.edu
}

September 14, 2016

JEL Classification codes: N71, N73, L92.

We would like to thank Dan Bogart, Jan Brueckner, Wally Mullin, Alessandro Oliveira, JeanLaurent Rosenthal, two anonymous referees, seminar participants at Sogang University, Pusan National University, the International Industrial Organization Conference and the Conference on Transport, Institutions, and Economic Performance: Historical Perspectives (UC Irvine) for helpful comments and discussion. We alone are responsible for any remaining errors. 
Abstract: We study the effects of trans-Atlantic passenger shipping cartels on tourist/business and migrant traffic. Collusion had a smaller effect on first and second class service relative to third class service. Its effects were proportionately stronger eastbound, but less important in absolute numbers given smaller eastbound traffic. Collusion-driven consumer substitution across classes was small but non-negligible. Thus, collusion affected migrant traffic far more than tourist/business traffic. We also confirm that collusion led to higher fares across all cabin classes, especially for steerage. We construct and calibrate an analytical model and show that the pattern of observed prices and volumes are consistent with a profit-maximizing cartel, thus buttressing the hypothesis that the collusion effects were causal. Finally, we document that collusion led to positive selection of migrants, as measured by literacy rates and financial resources. 


\section{INTRODUCTION}

The mass migration of Europeans to North America in the first decade of the $20^{\text {th }}$ century is the subject of an enormous scholarship, but relatively little has combined statistical and archival evidence to elucidate the effects of transportation costs on travel flows. Moreover, such evidence on non-migratory travel is even sparser. This is an area that merits careful empirical investigation because, as we show, there were considerable fluctuations in both fares and passenger flows, which differed greatly in magnitude for migratory and non-migratory travel. The dozen or so shipping companies that carried over ninety percent of the travelers organized a network of cartels that covered all major transatlantic routes. When these cartels were functioning, fares could rise drastically compared to when firms were competing. These higher cartel rates were effective at restricting migrant, tourist or business travel, and by extension affected economies and societies on both sides of the Atlantic. Furthermore, there is the possibility, which we empirically confirm, that cartels affected not only the level, but also the composition of travelers and migrants.

Previous work by Deltas, Sicotte and Tomczak (2008) estimated that when shipping cartels operated effectively, they restricted westbound steerage passenger movements by more than twenty percent. ${ }^{1}$ This paper makes a number of additional contributions over that prior work. The first contribution is to show that the cartel effects differed by class of service. This is important because it provides statistical evidence on the sensitivity of tourism and business travel to cartel operation, thus complementing Dupont, Gandhi and Weiss (2012), and Dupont and Weiss (2013), who provide a long-term perspective on transatlantic tourism using annual data. ${ }^{2}$ Our second contribution is to estimate the effects of collusion on fares, and show that cartels increased third class (steerage) fares the most. The third contribution is to provide evidence that 
the pattern of price increases and flow reductions are consistent (in a quantitative sense) with profit maximization, and thus likely causal. To demonstrate this, we develop an analytical model of cabin choice and calibrate it to the estimated cartel effects by cabin class and to the corresponding fares. The fourth contribution is to provide more systematic evidence of the differential effects of collusion on eastbound versus westbound traffic. Because a large fraction of migrants returned to Europe either temporarily or permanently, any difference in cartel effects eastbound and westbound may have influenced the relative importance of return migration. ${ }^{3}$ The final contribution is to provide direct evidence on the effects of collusion on the "quality" of US immigrants. Collusion-induced price increases are expected to displace the most financially constrained potential immigrants, who are likely the ones with the lower skills and economic potential. We formally test this possibility using auxiliary data on immigrant literacy and financial resources by ethnicity (which we map to country of origin).

Our primary dataset consists of passenger flows by route and class of service from 1899 to 1911. We collected these data from the exhibits of an American antitrust case brought against the shipping cartels at the end of 1911 (U.S. v. Hamburg-American Steamship Line, et al, 200 Fed. $806(1911))$. We categorize the relative effectiveness of shipping cartels across time and routes during our sample period, making this categorization from a careful analysis of primary and secondary sources, including copies of all of the cartel agreements, testimony and cables between executives in the participating firms. Thus, a subsidiary contribution of our study is to explain how these cartels functioned, and complement prior work on passenger shipping cartels by Keeling (2012), and Feys (2013), and analysis of freight cartels by Deltas, Sicotte and Serfes (1999), and Scott-Morton (1997). Our cartel study is informed by, and extends the work of Lamoreaux (1988), Levenstein (1995, 1996), and Clay and Troesken (2002, 2003), each of 
whom has studied the organization of cartels in different industries during this time period. The work by Grossman (2004) on cartel failure and endurance is also of special interest, as it describes enforcement mechanisms similar to those employed by the cartels we study, but in terrestrial rather than oceanic transportation. The economic analysis of passenger shipping cartels provides context for this historically important legal case. Prior to United States v. HamburgAmerican, the presumption in the United States was that the cartels were legal. ${ }^{4}$ Not only did the case provide a key precedent for the extraterritorial application of U.S. antitrust law (Molloy (1940)), but also influenced Congress' decision to grant antitrust immunity to shipping cartels in 1916 (Sicotte (1999)).

More broadly, this paper informs the literature on cartel operation and dissolution. Although this literature is voluminous, the quality and extent of our data is quite rare. Levenstein and Suslow (2014) have noted that both civil and criminal cases involving cartels often end with settlements or plea-bargains, resulting in little information revealed. Price and quantity data are quite rare. ${ }^{5}$ Beyond quantifiable data, we possess the complete library of passenger shipping cartel agreements covering all of the different North Atlantic routes over more than a decade. While previous studies have relied on the corporate archives of a single cartel member, the evidence from the antitrust case contains documents from many cartel members, and from the cartel secretaries. Some of the cartel agreements described here are more complicated than those typically described in the literature, whereas others are simpler. The evidence reveals the dynamic evolution of agreements across routes over time, which reached very sophisticated forms toward the end of our period. Importantly, this evolution occurred in the absence of any threat of antitrust prosecution. The lesson is that firms are capable of learning to collude more 
effectively through a process of experimentation, as in the Genesove and Mullin (2001) study of sugar industry collusion.

Our findings indicate that the shipping cartels were more effective in the steerage market than for first and second classes. The documentary evidence shows that the firms believed collusion was easier in steerage class because the product was more homogeneous, and that the firms could construct ingenious and effective pooling mechanisms. In contrast, in the cabin classes, there was greater product differentiation. Pooling proved impossible to implement, nor were firms able to agree to limit service competition. Thus, we find links between underlying product characteristics and the nature of cartelization. Because we possess a detailed history of cartel agreements and fare wars, we are also able to provide relevant evidence for the debate on the (in)stability of cartels. A large literature on cartel stability has followed from Stigler's (1964) seminal paper on this matter. Levenstein and Suslow (2006) report that cartels are mostly threatened by entrants and by difficulties in adapting their agreement to changes in the economic environment. In contrast, the experience of the passenger shipping cartels in our study supports the view that internal discord is more important than entry to cartel stability (at least in this particular case).

Finally, our paper is related to the migration cost and migrant selection literature. Recent contributions to this literature have highlighted the sensitivity of migration flows to migration costs for financially constrained migrants (see Bryan, Chowdhury, and Mobarak 2014, and Kleemans 2015). Our historical example provides a well-documented case of large sensitivity of migration to the cost of passage, especially for migrants planning to return home. The migrant selection literature has focused on how home and host country characteristics affect immigrant 
selection (e.g., Grogger and Hanson 2011). In our paper, we provide evidence of how the extent of migrant selection is impacted by the cost of migration, holding other factors constant. ${ }^{6}$

The next section highlights differences in the passenger classes and key features of the travelers' purchase decisions. The following section discusses the organization of the cartels, the challenges they faced with regards to price-fixing by service class, and how short-term pricefixing interacted with longer-term decisions. Subsequent sections present our empirical results and our interpretation of them. We conclude with a discussion of collusion effects on immigrant quality.

\section{TRANSATLANTIC PASSENGER TRAVEL AND TRAVELERS' TICKET PURCHASE DECISIONS}

Our data on passenger movements by route and class are from exhibits in United States v. Hamburg-American Steamship Line, et al, an antitrust case brought in federal court in New York in December 1911. ${ }^{7}$ The U.S. attorneys, granted subpoenas, collected vast records from the New York offices of the defendant shipping companies, and the offices of shipping conferences' (cartel) secretaries. These records consist of three main sets of information. First, there are records of the numbers of passengers carried by class on every voyage by cartel and non-cartel lines over the period 1899-1911. In addition to passengers by class, each voyage entry lists the ports or port regions of origin and destination. Second, there is a complete set of the cartel agreements employed by the lines on the different transatlantic routes during this period. Finally, the records include extensive correspondence between the conference secretaries, New York agents of the steamship lines, and lines' home offices in Europe and North America. This 
correspondence provides a unique inside look at the functioning of passenger shipping cartels, their internal and external conflicts, and their own assessment of the effectiveness of collusion. In this section we discuss the nature of product differentiation by class of service and the process by which travel was booked and carried out.

Passengers traveled on one of three classes of service: first, second, or third (steerage). The precise differences between the classes depended upon the exact vessel, and the policies of the line that owned it. Generally, first class accommodations were private berths of varying degrees of luxury, that carried with them access to specific dining rooms and facilities that were not available to other passengers. Passengers traveling second class often shared berths with a small number of passengers that they may not know, and had access to specific facilities reserved for that level. Third class passengers, by the early twentieth century, almost always traveled in closed berths, but with a larger number of bunks than in second class, and with access to simpler facilities (Keeling, 2012, pp. 236-238). First and second class fares diverged significantly by vessel and line, but it was not uncommon for first class fares to be $50 \%-100 \%$ higher than second class fares, which in turn might be $50 \%$ greater than third class prices (e.g., see the rates in exhibits 10, 11, 752, 762, 763). George Hannah, the Passenger Manager for Allan Line Steamship Company, stated in his court testimony that second class service began around 1880 , and at that time it was only marginally better than steerage, and cost about $\$ 10$ more. By 1912 , however, second class had become more differentiated, and fares reflected this: $\$ 31.25$ for steerage, $\$ 50$ for second, and \$70-\$80 for first class (Hannah testimony, pp. 1443-1444). ${ }^{8}$

Both westbound and eastbound, first class passengers were overwhelmingly tourists and business travelers; Keeling estimates that less than $10 \%$ were migrants. Third class passengers were nearly all migrants in both directions (some return or temporary). Second class, however, 
had a mix of migrants and other travelers. The precise breakdown is not known and differed by direction. Keeling estimates that about $80 \%$ of westbound and $60 \%$ of eastbound second class passengers were migrants (Keeling 2012, 229). The Scientific American Handbook of Travel, aimed at American tourists, said that those who could not afford first class would find second class an "excellent substitute," but "that the second cabin is more largely used by persons who are emigrating to the United States." (49). The relative fares across classes and the composition of travelers in each class were determined by demand conditions and market structure.

An important feature of transatlantic travel was the lag from the decision to travel and the purchase of passage to the actual travel as reflected in our data. The most striking demonstration of this is obtained from the examination of the effects of the 1907 US economic panic. The National Bureau of Economic Research dates the business cycle peak in the second quarter of 1907, yet the strong effect on flows is visible quite a bit later. Hourwich (1911) estimated that the full force of the recession was not felt until the fiscal year July 1908-July 1909, because people would be "saving the money with which their passage was paid for some months prior to their landing," and that "steamship tickets are quite commonly sold on small weekly payments" (Hourwich 1911, 625). The lagged effect of economic factors on travel is explained in part by the fact that approximately one-third of all westbound migrants traveled on tickets that were prepaid by relatives or friends in North America. ${ }^{9}$ Feys $(2013,90)$ notes, "Prepaid tickets sold during the winter months served as an indicator of the annual westbound traffic, which peaked between April and September." Prepaid ticket receipts listed the passenger name, steamship line, ports of embarkation and destination and the date of issue. The North American agent who sold the ticket would forward the monies along with notification to the steamship line, which would then communicate with the parties in Europe. The individual for whom the ticket was purchased 
would receive notice from the steamship line that a ticket had been purchased in their name, and then he/she could book a berth. There was considerable flexibility as to the vessel and timing of travel, because prepaid tickets were valid for one year from the date of purchase. ${ }^{10}$ It was not only migrants who sometimes booked far before they actually embarked. Tourists also often booked their first class berths six months or more in advance, in order to secure the most sought after cabins and be assured of space during what had become an annual mass "excursion season" by the early $20^{\text {th }}$ century. ${ }^{11}$

The description of passenger flows informs the econometric specifications that follow: we include seasonal controls, a trend, and economic variables likely to influence travel and migration, and lag those economic variables by two quarters. In the next section, we describe the historical functioning of passenger shipping cartels, which informs the construction of the collusion variables.

\section{COLLUSION IN PASSENGER SHIPPING AND UNITED STATES VHAMBURG-} AMERICAN, ET AL

Cartels were the rule rather than the exception in ocean shipping from the last quarter of the nineteenth century. Transatlantic passenger shipping firms' first sustained effort to establish cartel agreements dates to the mid 1880s (Mürken, Feys (2008)). Under British law, shipping cartel contracts were not illegal, but were unenforceable (Marx 1953). Nor did shipping cartels face prosecution in Continental Europe. Famously, German civil law permitted and enforced cartel contracts (Feldenkirchen 1992, 257). In the United States, passenger shipping cartels did not attract the attention of antitrust authorities until 1911, when the government brought a case 
against the colluding firms. The district court ruled the cartels permissible, and by the time the case reached the Supreme Court the cartels were no longer active on account of the war. The Supreme Court ruled the case moot in 1916, and the same year Congress passed the Shipping Act legalizing shipping cartels by granting them conditional antitrust immunity (United States $v$. Hamburg-American Steamship Line et al, 200 Fed 806 (1911), 216 Fed 971 (1914), 239 U.S. 466 (1916), Sicotte (1999)).

Cartel agreements stipulated the member firms, the geographic coverage and the class of service. For example, the seven lines that signed the North Atlantic Passenger Conference agreement of 1905 fixed rates on third class tickets between the United Kingdom to the United States and Canada (Petitioner's Exhibit 752), whereas “Agreement W” of 1908 specified minimum second class fares on each vessel of the thirteen signatory firms operating between England, northern continental Europe and North America (Petitioner's Exhibit 10).

Some steerage agreements included pooling arrangements. ${ }^{12}$ The pools were passenger, rather than revenue pools. Agreement AA (Petitioner's Exhibit 3) article one stated that the signatory firms "guarantee to each other the percentage participation... as defined and provided for in Article 3 of this contract of the entire steerage traffic forwarded by the parties to this contract from all European ports to and via the United States of America and Canada and vice versa in vessels owned, leased, chartered or controlled by them...Excepted are Italian and Oriental passengers forwarded by direct steamers through the Straits of Gibraltar. (Oriental means to or from Greece, Africa and Asia.)" Article 3 laid out the percentages for the lines both westbound and eastbound, ranging from 0.62 percent for the Allan Line's U.S. westbound services (Allan Line's services to Canada were not covered) to 26.53 percent for North German Lloyd's westbound service. The agreement (Article 6) called for firms "to pay a compensation 
price of four pounds sterling for each passenger (soul) carried in excess of the established proportion," and that these funds would be paid to the firms that did not meet their quota. Four pounds was less than the collusive ticket price in steerage on any route, which even on the most inexpensive routes and vessels was at least 5.5 pounds (Exhibits 752, 1307, testimony of Arthur Cauty, passenger manager of White Star Line, 1069-1070). Internal comments to the agreement noted that, "The stipulation of a compensation payment...forms one of the main features of the entire contract. The payment of such compensation is certainly not the intent and purpose of the contract, but it is the requisite means to deter the Lines from following the tendency to exceed their proportion...Compensation can be advanced and lowered by a majority of the Lines representing at least 75 per cent of the shares [quotas]."

The agreement called on an independent cartel Secretary to collect data weekly on passengers from the lines, to make accounts and stipulate payments (Article 10). If firms were found to exceed or fall short of their quota, they were "duty-bound to adopt measures calculated to bring about a correct adjustment." (Article 11) If these measures, typically rate adjustments, fell short, then lines representing $75 \%$ or more of the shares could mandate the appropriate rate adjustment. Yet, "no line [would] be compelled to fix its gross rate per adult steerager at less than 5 pounds sterling nor more than 8 pounds sterling." If firms stopped carrying passengers, their quota would be redistributed (Article 4). If they consistently fell short of their quota, they would be compelled to lower their rates. There is no evidence or discussion in the record of any firms following a strategy of carrying no passengers or carrying below quota to simply collect compensation payments.

Enforcement was a concern for all agreements, whether or not they had a pool. In Agreement AA, failure to comply with terms of the contract would result in fines, at least 250 
pounds per instance for a "small infraction," and at least 2500 pounds for a serious one (Article 20). An Arbitrator, alternately chosen in England or Germany, would fix the precise amounts (Article 24). In Agreement W (Exhibit 10) on second class service from northern Europe, the arbitrator was Henry Wilding, a British citizen with a long career in passenger shipping, and all arbitration would be in London (Article 16). In the cartels with pooling agreements firms nearly always had to post performance bonds, and the amount of the bond depended on a firm's pooling percentage. The documentary evidence confirms that statistics were collected, compensation payments were made, firms adjusted rates when carriage deviated from quotas, and disputes were sent to arbitration. ${ }^{13}$

There were important differences between cabin (first and second class) agreements and steerage cartels. First, none of the cabin agreements included a pool - collusion took the form of fixed minimum rates for each signatory's vessels. As Hermann Winter, passenger manager for North German Lloyd, explained in his testimony, this was not for lack of effort. Firms had negotiated "over and over again but did not succeed" in reaching an agreement to establish a cabin pool (Testimony, 1182-1883). Winter judged it impossible, and Erich Mürken (1922, chapters 5-6), who participated in these negotiations alongside Hamburg-American Director Albert Ballin, concurred. The key roadblock was that firms could not decide on quotas and a mechanism for adjusting rates across the many different vintages and qualities of ships (Mürken 1922, 111-114). Mürken stated that an added complicating factor was that whereas steerage fares varied by ship, cabin fares varied by ship and by location on the ship. This was especially the case for first class - first class transatlantic fares on Hamburg-American Line steamers circa 1910 ranged from 350 marks to 2000 marks, and a high season passage in the imperial suite cost 20,000 marks (Mürken 1922, 112). This high degree of product differentiation in cabin class 
meant that passengers on the same voyage paid radically different fares, and a single compensation rate for exceeding one's quota was impossible. The negotiators deemed a "headpool" (fixed quotas of total passengers) like that employed for the steerage traffic impracticable. The Agreement AA Conference Secretary advocated pooling revenue for both first and second class combined, reasoning that the highest second cabin fares for some vessels were actually higher than some of the first class fares on other vessels, and because some of the staterooms on some of the steamers were interchangeable, "used as needed for either first or second cabin" (Mürken 1922, 113; Keeling 2008, 238-240). Most of the lines disagreed, however, because second class demand was growing far more rapidly than first class demand, and therefore fixing revenue quotas would give rise to controversy because some lines were much better positioned for those demand developments than others.

In Mürken's opinion the key roadblock to reaching an agreement on revenue sharing was because the firms that had a modern fleet did not want to fix quotas based on total first or second class capacity, because that would lead to what they considered too generous a quota for the lines with older fleets (Mürken 1922, 115). This was vital because cabin passengers had a higher willingness to pay not only for luxury, but also for vessel speed, and this fueled a constant competition among the firms to introduce ever more luxurious and faster ships. Joseph Bruce Ismay, executive of White Star/International Mercantile Marine and famous through his survival of the Titanic disaster, stated in his testimony that firms were under enormous pressure to build new ships, and that older vessels were "carrying passengers at a heavy loss because they are out of date" (1026). Firms considered, but did not agree to proposals such as that of HamburgAmerican Line's Director Albert Ballin to create a common fund, which firms would pay into based upon existing capacity and which would be used to purchase and destroy older vessels 
(Mürken 1922, 117-118). Attempts to collude on quality of service, or to limit capacity, failed, and these failures cut into the profits of the shipping firms even during periods when collusion was otherwise successful.

Thus, first and second class cartel agreements were rate agreements in which minimum fares were specified for each firm's individual ships. Care was made to ensure sufficient difference between the lowest second class fares and steerage fares, because firms wished to avoid steerage passengers "escaping" from consideration in the pool and traveling on the relatively unregulated second class. In Agreement AA, it was noted that for each steamship the lowest second cabin fares must exceed the highest third class fares by at least two pounds sterling, and that any cabin passenger having paid a fare below that threshold would be included in the pool (Exhibit 3, Articles 2 and 13). The Mediterranean Steerage Traffic Agreement contained a similar stipulation (Exhibit 6, Article 4). Moreover, the commissions firms were allowed to pay ticket sales agents on each class of passenger were strictly regulated. Despite these safeguards, difficulties arose. Because firms that exceeded their steerage quota increased their steerage rates as part of the agreement, these rates quickly approached previously agreed minimum second class rates. For example, in the spring of 1909 Red Star Line cabled the Agreement AA conference secretary, "The small difference between 2 nd and 3rd class rates becomes more and more disagreeably remarkable. Not alone that the adjustment of the Pool by raising the 3rd class rates is impossible but also a large number of steeragers are literally forced into the 2nd class and thus diverted from the Pool. On the other hand the 2nd class becomes overburdened, and elements are brought into it which according to their social standing do not belong there and they cause serious complaints from the real 2nd class passengers." Accordingly, Red Star proposed that all lines advance their 2 nd class rates by 20 shillings (Cable from Conference Secretary to 
Parties, June 26, 1909, Petitioner's Exhibit 1376). When that did not occur, lines that were short of the their quota reluctantly reduced their steerage fares (Cable from Conference Secretary to Parties, July 6, 1909, Petitioner's Exhibit 1379). Clearly, the three service classes were interrelated, and the efforts of firms to collude reflected that fact.

In many, but not all, cases the cartel agreements were signed by all of the firms active in a particular route. ${ }^{14}$ When they did not, firms coordinated action against outside lines. These outside firms were relatively minor players, such as the short-lived Northwest Transport, and the Russian Volunteer Fleet, and they faced a variety of tactics from the cartel members, most famously the use of "fighting ships" that would mimic the schedules of the non cartel firms and charge ruinously low fares, and the punishment or shutting out of ticket agents who booked passengers on outside firms' vessels (see the discussion in United States $v$ Hamburg-American).

The threat from non member firms, however, was far less serious than the possibility of internal breakdown. The rupture of an agreement might manifest itself as a full-fledged rate war, or simply a lapse in enforcement, characterized by widespread cheating on the agreements. The most significant rate war occurred from late 1903 through 1904, and spread to all routes and classes of service. The warring firms reached a tentative peace in early 1905 . In some cases the old agreements were re-invoked, and in others new agreements were established. However, collusion did not function smoothly thereafter, with frequent accusations of secret rate-cutting, until a second rate war broke out in the second half of 1907. This war ended when nine steamship companies achieved a comprehensive pooling agreement that covered nearly the entire passenger traffic between northern Europe and North America (Mürken, chapters 12-13, Hyde, chapter 4; testimony of Hermann Winter and Arthur Cauty in United States v HamburgAmerican, and Petitioner's Exhibit 2). We identify the dates of full effectiveness, rate wars and 
lapses by careful examination of the historical record, as detailed in the extensive testimony and exhibits of the court case, Stevens (1914), Mürken (1922), Hyde (1975), Keeling (2005), and the press (especially the New York Times, the New York Journal of Commerce, the Times of London and Fairplay). Table 1 illustrates the pattern of cartelization, rate war and lapses across the main routes during the period of our study. We use this classification scheme for the cartel variable in our econometric analysis.

In January 1911 the United States brought suit against the firms that were signatories to Agreement AA. The prosecution argued that the combination was an illegal restraint of trade under the Sherman Act (Brief for the United States). The documentary evidence of collusion was overwhelming and undeniable. Beyond the printed agreements, the U.S. attorneys also pointed to evidence that the cartel, through subsidiary agreements in conference, had engaged in unfair predatory conduct against outside lines. The steamship lines claimed that the antitrust laws did not apply because the combination applied to international commerce, and the Sherman Act only applied to interstate commerce. Further, they noted that the combinations were formed overseas and were legal in the European countries where they were formed. They also argued that collusion was necessary to provide stability to the trade, and had been beneficial to consumers as evidenced by the improved conditions across all classes of service over the previous quarter century. The defendants maintained that their actions against outside lines were not unfair, as they "merely protected their own...traffic against the attacks of outside lines." (Brief for North German Lloyd, Brief for the Cunard Line). Their argument received a boost when in spring of 1911 the U.S. Supreme Court decided the Standard Oil and American Tobacco cases, establishing a "rule of reason" interpretation of the antitrust statutes. Price-fixing did not appear to be per se illegal any more. 
As a consequence, when the case was argued in 1912 the prosecutors argued that the rates the cartel charged were unreasonable, whereas the defense argued that they were reasonable. However, both sides could only attack this question in a manner that bears little resemblance to that employed by contemporary antitrust litigators and their economic consultants. The prosecution succeeded in getting the witnesses to acknowledge that when competition was open, during rate wars, the lower rates attracted an increased volume of passengers, (for example, see testimony of Sidney Lister, Cunard Line, 1561). However, the defense argued that such an increase was not a beneficial increase for the United States: "You get during the rate war the dirty people...the very people who in times of regular stable business we are keeping out...every one whatever who has a few shillings to go to America. The natural result is that the steamship companies might be inclined to accept as many passengers as they can to make both ends meet, and the likelihood of the United States being afflicted with a very, very large number, an enormous number, of undesirable passengers.” (Testimony of Sidney Lister, 1515).

The decision of the district court, not issued until 1914, was that the there was not convincing evidence that the rates charged were unreasonable, and that the agreements and restrictions upon the agents were not a violation of antitrust law, except that court deemed the practice of "fighting ships" an "obnoxious feature" of the cartel and issued an injunction against it. In making its decision, the court noted that the House of Representatives Committee on Merchant Marine had recently issued a report on shipping cartels, and found that in the absence of these arrangements, "The lines would either engage in rate wars which would mean the elimination of the weak and the survival of the strong, or to avoid a costly struggle they would consolidate through common ownership. Either would mean monopoly fully as effective, and it is believed more so, than can exist by virtue" of the cartels. (U.S. House Committee on 
Merchant Marine and Fisheries 1914, 295-303, cited by the court at 216 Federal Reporter 974, October 13, 1914). The case was appealed to the Supreme Court, which ruled that the Sherman Act was indeed applicable to the case, but that it would not rule on the merits because the World War I had rendered the agreement void and the case was therefore moot (239 U.S. 466, decided January 10,1916$).^{15}$

\section{PASSENGER VOLUME DATA AND VARIABLES}

In Deltas, Sicotte and Tomczak (2008), we provide econometric estimates that cartels reduced westward steerage flows by approximately twenty percent. In this paper we use many of the same primary data sources, with minor changes, to estimate a number of additional econometric specifications that extend our knowledge of these cartels. In particular, we investigate whether the cartel agreements had a differential impact on the passenger flows of each class of service, and the extent to which cartel operation led to substitution between the three service classes. We also look at the differential effects between eastbound and westbound directions of travel. The substitution pattern is important not only in providing an assessment of the primary incidence of cartelization, but also because it helps improve our estimate of cartels' impact on immigration. The distinction between the eastbound and westbound directions is equally important, since they jointly give a more precise assessment of the effects on net flows.

To address these questions, we obtain data series on passenger flows by service class from the exhibits in the antitrust case. Although reported by voyage, we aggregate the data by quarter and by the routes shown in Table $1 .{ }^{16}$ The aggregation of the data by route reflects the organization of the cartels and the partition of hinterlands to each port. ${ }^{17}$ There is large seasonal variation in the level of flows, which can somewhat obscure main trends. Though in the 
econometric analysis, we use the quarterly series for reasons detailed in Section 2, and control for the seasonal variation by seasonal dummies, we display in Figures 1-3 flows at annual frequencies for the three highest volume markets. A general positive trend and the significant shock whose timing is apparently associated with the U.S. Panic of 1907 are evident from these figures. The effect of the shock tends to be negative for westbound travel, but positive for eastbound (reverse migration) travel; it is also more pronounced for steerage than for cabin service.

The most important independent variables are those that reflect the cartelization status of a route at each quarter. The construction of these variables is based upon the exhibits in the antitrust case and a reading of the contemporary press and literature, and is described in the preceding sections. The values of these variables are schematically depicted in Table 1 . The variable $A G R E E M E N T_{j t}$ takes the value of 1 if there is a cartel operating in route $j$ in period $t$; this variable takes the value of 0 in periods that no cartel agreement was signed that covers route $j$ and in periods that a cartel agreement was signed for route $j$ but there was a price war. Values of 1 for this variable correspond to dark and light shaded cells in Table 1. The variable $N O R M A L_{j t}$ takes the value of 1 for route $j$ and period $t$ when there is an agreement that operates normally, i.e., when firms co-operate as stipulated by the agreement; it takes the value of 0 in all other periods. ${ }^{18}$ Values of 1 for this variable correspond to dark shaded cells in Table 1. Note that in the regression model, the variable $N O R M A L_{j t}$ captures the incremental effect of a normally operating cartel agreement beyond any effects reflected in the coefficient of $A G R E E M E N T_{j t}$. In Figures 1-3, the cartel status in effect for most of the year for each route is reflected by the plot symbol. If there was a normally functioning cartel in the particular class of service, direction of travel, and route for most of the year, the plot symbol is a large solid circle. 
Otherwise, the symbol is a small hollow circle. A quick inspection of these figures, and a visual "control" of the trend, suggests that collusion lowers flows for the third class, but has very small effects for the first and second classes. Summary statistics for quarterly passenger flows per route and by cartel status are shown in Table 2, Panel A. As in the figures, collusive regime refers to normally operating cartels. Flows are smaller during those periods for steerage. For cabin service, the effect appears to be the opposite, but this is because these summary statistics do not control for route effects (the low traffic route between Scandinavia and the United States was never cartelized for cabin service, but was cartelized for steerage).

We also utilize a number of economic variables that are expected to affect the demand for travel. These variables relate to labor market and macroeconomic conditions in both origin and destination countries and are the same as those employed in Deltas, Sicotte and Tomczak (2008). ${ }^{19}$ We provide here a very brief description of them. We use the real wage series from Williamson (1995) to construct real wage indexes for the origin and destination regions of our routes. Origin and destination does not refer solely to the countries where the ports in each route are located, but to the entire region from where passengers using those ports originate. Because most of the European regions consist of multiple countries, we weigh the real wages of those countries by the proportion of migrants that they supplied during this period. ${ }^{20}$ The variable $D E S T W A G E_{j t}$ is the deviation from trend in the wage in the destination region, while the variable $O R I G I N W A G E_{j t}$ is the deviation from trend in the wage in the origin region. We also use an index of U.S. factory employment (NBER) and U.S. unemployment (Lebergott 1964). The variable $F A C T E M P L_{j t}$ takes the value of the first difference of factory employment, while the variable $U S U N E M P L_{j t}$ takes the value of the U.S. unemployment in routes that terminate or originate from the United States, and the value of zero for routes that originate or terminate in 
Canada. ${ }^{21}$ We also use Maddison's (1982, 172-173) GDP indexes for the individual countries, and constructed GDP series for our regions using the same weighting methodology employed for the wage series. The variable $D E S T G D P_{j t}$ is the deviation of destination GDP from its trend, capturing whether the destination economy is on business cycle trough or peak. Similarly, the variable $O R I G I N G D P_{j t}$ is the deviation of origin GDP from its trend. As with the wage variables, destination and origin regions correspond to the route destination and origin regions. Summary statistics of the economic variables used to generate our controls are reported in Table 2, Panel B. One can see that collusive periods correspond to periods where employment was higher (and growing faster) but also periods where unemployment was higher as well. Thus, controlling for economic conditions can potentially be very important (recall that the controls are appropriately defined to be differences of these indexes). Further information on the construction of these variables is found in Deltas, Sicotte and Tomczak (2008). As demonstrated in that paper, the use of these economic variables is not sufficient to capture the very strong effects of the 1908 economic crisis in North America. The use of a dummy variable for year 1908 yields more appropriate (and more conservative) results on cartel effects. Whereas we expect the economic variables to take signs consistent with immigration "push" and "pull," tourist traffic should be increasing in economic activity on both sides of the Atlantic. ${ }^{22}$

\section{EMPIRICAL ANALYSIS OF PASSENGER FLOWS}

THE ECONOMETRIC MODEL

The empirical strategy follows Deltas, Sicotte and Tomczak (2008), modified to allow us to investigate how collusive effects vary across cabin classes and the direction of travel. This 
strategy is summarized in this sub-section. We take advantage of the panel nature of the data and employ a modified difference-in-difference estimation approach, where the effects of interest are identified from the over-time variation in cartelization in particular cabin classes and routes, controlling for a linear trend in flows, and using a number of additional controls. Our dataset is not rich enough to allow us to employ time fixed effects, since many agreements start or end in the same period. However, note that seasonal effects are accounted for through the use of indicator variables.

The general base specification, estimated for every class, $c$, and direction, $d$, is

$$
\begin{aligned}
& \log \left(Q_{c d j t}\right)=\kappa_{c d}+\alpha_{c d} \text { AGREEMENT } T_{c d j t}+\beta_{c d} N O R M A L_{c d j t}+\gamma_{c d} \text { FACTEMPL }_{t}+ \\
& \delta_{c d} D E S T G D P_{d j t}+\zeta_{c d} \text { ORIGINGDP }_{d j t}+\theta_{c d} Y E A R 1908_{t}+\lambda_{c d} \text { TREND }_{t}+ \\
& \varphi_{c d}^{S P} S P R I N G_{t}+\varphi_{c d}^{S U} S U M M E R_{t}+\varphi_{c d}^{F A} F A L L_{t}+\psi_{c d j}+\varepsilon_{c d j t}
\end{aligned}
$$

where $Q_{c d j t}$ is the number of passengers in quarter $t$, on route $j$, traveling in class $c$ in direction $d$, the cartel and economic regressors are as defined in the preceding section, $T R E N D_{t}$ is a quarterly trend, SPRING $G_{t}, S U M M E R_{t}$ and $F A L L_{t}$ are seasonal dummies (winter is the omitted season), $\psi_{c d j}$ are route effects (the value of which differs by class and direction), and $\varepsilon_{c d j t}$ is a disturbance term. ${ }^{23}$ The distribution of $\varepsilon_{c d j t}$ is characterized by large heteroskedasticity, with variance differing systematically both across different routes and different quarters. Therefore, all variants of this linear model are estimated via Generalized Least Squares (GLS) which improves estimation efficiency by attaching higher weights to observations that are characterized by lower variance. ${ }^{24}$ Passenger flows are assumed to be trend-stationary with deviations from trend being driven by a list of stationary variables. Since separate regressions are estimated for Westbound and Eastbound travel and for each class of service, we obtain six sets of parameter estimates for each specification (as indicated in the parameter subscripts). ${ }^{25}$ 
The cartel and economic variables are lagged by two quarters because the passenger data is for arrival date at the destination. Although the ocean part of the journey might be as short as one week depending upon the route and vessel, the inland journey might have begun much earlier. This is especially true for migrants from Eastern Europe, who often had to cross borders, making several train connections, and endure squalid conditions at border "control stations" for lengthy periods (Szajkowski 1977). The full journey could take months, and required months of planning before that (see Section 2 for a full discussion). First class travel was often purchased as a round-trip, and as much as six months in advance. Deltas, Sicotte and Tomczak (2008) describe analysis and discussion that supports the choice of a two quarter lag. Related to the issue of lag structure is the possibility that collusion largely redistributed flows across time. If that were the case, then the various cartel-related coefficients would appear larger in absolute value in our regressions. This possibility is investigated (and rejected) below.

We estimate a number of econometric specifications that differ from the above regression in a several ways. First, the economic activity controls displayed in our base econometric model capture the volume of economic activity in North America and Europe. These controls reflect both opportunities for migrants for employment and also the income for non-migrant (business and leisure) travelers. Some specifications use an alternative set of controls that more closely reflect labor market conditions. This alternative set uses the U.S. unemployment rate (rather than changes in U.S. factory employment) and deviation from trend of origin and destination wages (rather of GDP). Both sets of economic controls also include a dummy variable for the year 1908, which coincided with a very deep recession in North America, and which is therefore expected to have disproportionately large negative effects on migration to the United States. ${ }^{26}$ Second, in some specifications we drop the dummy for the year 1908 and replace it with quadratic and cubic 
expansions of the economic variables, to see whether nonlinearities in these variables capture the big shock of 1908. Third, we add indicator variables for the first year that a cartel is operating and the first year after a cartel has broken down. This is done to capture the possibility that there is inter-temporal substitution (after a cartel comes in force, consumers may delay passage to see if collusion breaks down; after a cartel dissolves, consumers putting off travel may be enticed by the discounts). Finally, we drop the distinction between the presence of collusion and whether this collusion was operating normally. For brevity, the results of the last two variations are discussed but not reported in tables.

\section{RESULTS}

Table 3 reports our main results, and is followed by three tables that report various extensions and robustness checks. The first three specifications of Table 3 report regressions for westbound traffic, while the last three report regressions for eastbound traffic. On westbound traffic there is a reduction in flows for all classes of service during the period of normal operation, with the reduction being largest for third class service (recall that the total effect of normal operation on passenger flows is given by the sum of the two cartel coefficients). ${ }^{27}$ A likely explanation for the differential impact is that the cartels raise steerage fares more than they raise cabin class fares (see analysis in next section). The coefficients on the economic and seasonal variables tend to support the view that few first class passengers were migrants (Keeling estimates 10\%), while second class passengers were a mix of tourists and migrants. In particular, the coefficient on origin GDP is zero for first class, but negative for second and third class passengers, while the coefficient on U.S. factory employment is near zero for first class, positive but small (and not significant) for second class, and large (sometimes significant) for steerage. Similarly, the 
coefficient for destination GDP is positive for all classes, but far bigger for steerage. All of the models consistently show an increasing trend to flows, and the seasonal dummies show the regular variation, with a strong peak in the summer (first and second) or spring (steerage) of each year. The year 1908 stands out as a major deviation from that trend, with flows off by more than fifty percent for steerage, and smaller decreases for the other classes. This is consistent with the interpretation that this dummy reflects the large economic dislocation during 1908 and the passenger composition of each service class.

On eastbound traffic the negative effect of cartel operation on traffic is more pronounced for all cabin classes, and especially for steerage. Price sensitive round-trip travel (tourist and transient migrant) combined with less sensitive permanent immigrant flows is one driver of the stronger eastbound effects. If collusion results in a particular number of round-trip travelers forgoing the round-trip, this would affect the number of passengers by the same amount in both directions. But with eastbound flows being smaller, the corresponding percentage effect would be larger. ${ }^{28}$ As with westbound flows, the parameter estimates for third class are larger than those for first and second class. With regards to the other control variables, the eastbound traffic also exhibits an increasing trend, but the seasonal variation is somewhat different. The seasonal coefficients indicate eastbound peaks for first and second class in the spring, but for the third class the peak is in the fall. This is consistent with the literature, which noted that the excursion season for American tourists departing for Europe in late spring and returning in late summer, while many eastbound steerage passengers were temporary migrants returning after the North American harvest. The Year 1908 indicator is positive (and significant at the $10 \%$ level for second class and steerage); as expected, the deep financial crisis contributed to a substantial reverse migration. Among the other economic variables the only statistically and economically 
significant impacts are from North American GDP, which is positive for second and third class. This suggests that, after controlling for the dramatic effect of 1908 crisis, eastward travel was largely of the business and leisure variety. ${ }^{29}$

In Table 4 we re-estimate the models of Table 3 substituting labor market economic controls (wages and unemployment) for economic activity controls (GDP and industrial employment). The economic controls have the correct signs for westbound flows, and are statistically significant for steerage for destination real wages and U.S. unemployment. The origin (European) effects appear to be somewhat muted, particularly in the case of wages. The economic effects appear weaker for the two cabin classes, for reasons discussed earlier. The coefficients of interest, however, are not materially affected by the use of the labor market controls, though they are a bit smaller quantitatively. In the eastbound direction, higher U.S. unemployment and higher European wages are strongly associated with reduced eastward steerage flows, and to a lesser extent reduced cabin class flows. These results suggest that, in accordance with the historical literature, a significant portion of the eastward flows consisted of recent immigrants from Europe who had some success in North America and returned to Europe for a visit or permanently. As with Table 3, the 1908 dummy is positively associated with eastbound flows.

In all the regressions reported to this point, the dummy for the year 1908 is used to capture the large negative economic shock in the North American economy during that year. We do not argue that this dummy reflects only the effects of the crisis, but rather we want to ensure that any failure of the other economic controls to capture that extreme event does not contaminate our estimates of the cartel agreement variables. As a robustness check, we report in Table 5 regressions in which the 1908 dummy was replaced by higher order terms of the economic 
variables to capture the non-linearity inherent in major economic dislocations. These higher order terms are jointly statistically significant in half the cases: the higher order terms capture much of the negative shock of 1908 , but that the severity was so big that even cubic terms do not fit it very well. Relative to the results using the 1908 dummy, those using the higher order terms result in smaller cartel effects. However, the estimates that were significant retain their significance in all cases but one.

A final question is whether the cartel coefficient is affected by inter-temporal substitution driven by the price fluctuations. If there were such substitution, the year after collusion breakdown passenger flows would be higher as consumers who were priced out of the market during the collusion years booked travel at the lower fares. We find that there is no evidence of inter-temporal substitution, perhaps because the migration decision is of a "now or never" kind, and/or perhaps because consumers had purely adaptive expectations for prices. In fact, in regression results that are not reported for brevity, the year after collusion breakdown yields lower than expected flows for all three classes for westbound travel, and for the first class heading eastbound (one of these statistically significant). Only for eastbound second and third classes were these effects positive, neither of them significant. Conversely, one might expect passenger flows to be particularly depressed in the first year of collusion, since people may hold off travel in the hope that prices may come down. Again, there is no evidence of this. Of the corresponding effects, three are positive, three are negative, and the only statistically significant one is positive. ${ }^{30}$

There are also a number of robustness checks we have done and which we do not report in any tables in the interest of saving space. The first robustness check involves possible misclassification of collusive status. There are two instances when the record in our disposal is 
not conclusive with regards to cabin service. The record indicates that there was no formal agreement on first and second class service to and from Scandinavia throughout the period we study, and we have classified that service as free of collusion. However, the possibility arises that the firms coordinated tacitly, given that they did form an agreement on the more important steerage service. We have repeated the analysis in Table 3 coding cabin service involving Scandinavia in the same way we coded third class service, and obtained nearly identical results. A second instance of ambiguity about the collusive status involves the Mediterranean agreement in its early period. This is coded as collusive, but the record makes no explicit mention of a distinct agreement covering cabin service. The most reasonable interpretation is that coordination covered all classes of service in a similar manner, but we have re-estimated Tables 3 coding this service as competitive in the early period. When Mediterranean cabin service is classified as such, the estimated effect of collusion appears smaller. This suggests that the Mediterranean route is observationally similar to collusive routes for the years in question, as mentioned in the record and treated in our standard classification. The second robustness check involved estimating Table 3 using a one or two quarter lag. Examining the coefficient of normal cartel operation and also the sum of the two cartel parameters (the total effect), which are the most important and precisely estimated effects, we note the following. The point estimates are generally not very different in value (relative to the standard errors). Moreover, the results are not strongest for the two quarter lag: the one quarter lag leads to statistically significant parameter estimates slightly more often and parameter values that are often higher. The three quarter lag results are comparable in these measures to the two-quarter lag. Thus, even though the two-quarter lag is more appropriate based on the documentary evidence, this particular 
choice is not crucial for the findings we obtain, and it is not the one that makes them "strongest." 31

\section{PRICE DATA AND ANALYSIS}

Collusion affected passenger flows through the prices charged to passengers. In this section we assemble from various sources information for fares during our sample period to demonstrate and measure the extent through which cartelization impacted fares. The results of this analysis will also be used in the next section to evaluate the framework through the use of an analytical model.

Price data for this period are less systematically available than passenger flow data. We assembled price data from two distinct types of sources. The first source consists of price series put together by economic historians. Most of these price series are annual averages of westbound steerage fares for selected ports and carriers, and miss the first two years of our passenger flow sample (some series also contain gaps). The most complete of these series is that in Keeling (2008), which also seems to overlap with information reported elsewhere. ${ }^{32}$ There are some more limited data on two ports that covers all three classes of service for westbound passage and are reported on a quarterly basis (Keeling 2007). All fares have been converted to U.S. dollars, and inflation adjusted to 1902 based on the historical CPI estimates of the Federal Reserve Bank of Minneapolis. This data is sufficient for formal regression analysis, albeit one that we would attach less confidence compared to that of passenger flows. There is insufficient information on eastbound fares from these published sources for any meaningful analysis. 
The second source consists of fare quotes that we have obtained from primary sources at a very disaggregated level: they refer to the fares charged on a specific vessel for a particular class of service on a given route at a particular time. For periods of cartel operation, these fares are from cartel fare schedules as obtained from the exhibits of the antitrust case (exhibits 10, 11, 33, 713, 715, 716, 717, 725, 729, 730, 731, 733, 734, 736, 737, 738, 740, 741, 752, 753, 757, 758, $762,763,937,950,1026,1307$, and 1869), as well as reporting in the Journal of Commerce (New York), the New York Times, and as discussed by Erich Mürken (1922) and Francis Hyde (1975). These price quotes are for the periods of collusion only, but we were able to identify 122 rate quotes for the same vessel/line/route/class combinations for adjacent time periods during which firms were engaged in open competition. For such periods of price wars, we use data from the Journal of Commerce, the New York Times, Hyde, and Mürken.

Table 6 reports the results of regressions of the log of real fares on the cartel dummy and other variables using the data series published by Keeling $(2007,2008)$. The first two columns consist of the analysis of annual steerage fares from a variety of ports (port fixed effects are included). Collusion increased prices from these ports by approximately $14 \%$, and the result is robust to whether we include a dummy for the year 1908. The remaining columns consist of the analysis of westbound fares from Liverpool and Rotterdam, which are reported on a quarterly basis by cabin class. Columns 3 and 4 cover steerage fares; collusion appears to have raised these fares by nearly 30\% when the year 1908 dummy is included, and by a somewhat smaller amount when it is not. The last two columns cover first and second class fares, pooling them together but including a dummy for first class service. The effects of collusion for cabin service were approximately $20 \%$ when a dummy for 1908 is included, and somewhat lower when it is not. It is noteworthy that this quarterly series yields more pronounced collusion price effects than the 
broader based annual series. Part of the difference is due to the time periods covered, as the annual data start in 1901, when cartels were probably less stringent in their pricing (annual data start in 1903); the rest reflects heterogeneity between ports and lines. In fact, line heterogeneity appears to differ by class of service. For example, looking at the quarterly series, we see that steerage service from Liverpool on Cunard was substantially cheaper than steerage from Rotterdam on Holland America, but the reverse is true when comparing first and cabin class service. Incidentally, prices seem to be lowest in the winter with smaller variation among the other seasons. These differences are quantitatively more important for cabin class service (and in fact not statistically significant for steerage).

The 122 fare quotes we have obtained ourselves from primary sources, and which compare collusive fares with corresponding price war fares for specific ships, do not cover a broad enough period to permit regression analysis. We provide some discussion and summary statistics in this paragraph. Given that the analysis of flows is at the route level, we have computed the average of the cartel induced fare changes by averaging the price quotes at the route and direction of travel level. There are only a handful of quotes for most of the routes where quotes are available, and as a result the route level changes contain substantial variation. Aggregating fares at the direction/cabin class level, we are able to obtain fare changes for five out of six possible combinations. The number of quotes for first and second class eastbound is 50 and 38 , respectively; the corresponding collusion induced fare increases are $40 \%$ and $23 \%$. There are 22 quotes for westbound steerage, with an average collusion fare increase of $68 \%$. There were only 9 quotes for eastbound steerage service, and 3 for westbound first class service, with associated collusion price effects of $58 \%$ and $22 \%$. The last two figures are very noisy, and to an extent so is the one for westbound steerage. There are no fare comparisons on second class westbound 
service. These price effects, albeit imprecise in some cases, provide a second measure of how collusion affected prices. ${ }^{33}$

The collusion induced price increases from the quotes we have obtained are higher than those based on the regressions of westbound fares (especially for steerage). Both sets of results, however, point to large fare increases that could easily generate the observed reductions in passenger flows. We next take up the issue of how consistent are the observed fare and flow data with optimal collusive behavior and substitution of passengers across fare classes.

\section{EVALUATION OF THE FRAMEWORK AND DISCUSSION OF THE EMPIRICAL RESULTS}

\section{AN ANALYTICAL MODEL OF DEMAND FOR TRAVEL BY CLASS OF SERVICE}

In this section, we combine the estimated quantity and price effects of collusion with a standard vertical differentiation model, which allows us to accomplish two things. First, we calculate how many passengers traveling in a particular class of service in the absence of collusion, would travel in a different class of service (or not at all) in the presence of collusion. These collusion effects differ from those in the volume regressions because they incorporate the displacement of travelers from one class to another. The premise in these calculations is that at the collusive prices, the marginal first class passengers choose to downgrade to second class, but do not choose to forgo travel altogether or to travel in steerage. This presumption is reasonable given that the low end of the distribution of first class passengers are not too different in their preferences than the high end passengers in second class service. Similarly, the second class passengers may choose to upgrade to first class (if the price difference between these classes 
decreases), or downgrade to steerage; they will not choose to forgo travel altogether. The presumption is reasonable given that the low-end of second class passengers are migrants who simply have more funds at their disposal. A higher cost should not deter them from traveling altogether, since steerage travel would be still be affordable to them. Under this reasoning, the only passengers who would forgo travel due to the increase in prices are those traveling in steerage. ${ }^{34}$ Though clearly a simplification, this reasoning is formally obtained from our modeling framework, which is a modification of the standard vertical differentiation model (e.g., Mussa and Rosen 1978, Tirole 1988).

The second contribution of the modeling framework is that it permits us to evaluate the plausibility that collusive behavior underpins the observed price and quantity effects. The model implies a particular pattern of collusive price changes in terms of absolute levels and also in terms of relative price increases for each class. We compare these with the observed relative and absolute price increases. Moreover, the model yields estimates of consumer willingness to pay for different classes of service and the marginal cost of delivering those services. These estimates form an additional "reality check" for our interpretation of the results.

In models of vertical differentiation, consumers are distinguished by their willingness to pay for the quality of a service. We adopt the simplest specification and assume that a potential traveler's willingness to pay for passage of quality $x$ is $U=\theta x$, where $\theta$ is that consumer's marginal willingness to pay for quality. The value of $\theta$ varies across consumers: some travelers are willing and able to pay a lot for higher class service, while others cannot or do not want to. Since "quality" is just an index, we measure it in units so that $\theta$ is uniformly distributed on the $[0,1]$ interval. We denote the quality for the first, second, and third class services by $x_{1}, x_{2}, x_{3}$, respectively, and assume they are the same across firms. This is a simplification, since 
differences across ships and their departure dates induce some differentiation across firms. But this assumption significantly simplifies the analysis, leading to solutions that do not depend on the number of firms. It is also necessary for the "calibration" of the model with the price data we have. For similar reasons, we assume that the marginal costs for each class of service, denoted by $c_{1}, c_{2}, c_{3}$, are the same across firms, as are the prices for passage, denoted by $P_{1}, P_{2}$, and $P_{3}$. Note that this discussion abstracts from the direction of travel. Indeed, we will not consider round-trip travel in the quantitative analysis, though we will discuss the implications of not doing so at the end of this section.

A prospective passenger chooses the class of service that yields the biggest surplus for him or her, i.e., the class of service for which willingness to pay exceeds the price by the most. If willingness to pay is lower than the price for all three classes of service, the prospective passenger does not travel. Given that the higher the value of $\theta$, the more a prospective passenger values high quality service, passengers with the highest values $\theta$ will travel first class. Let the interval of $\theta$ for these passengers be $\left[\theta_{1}, 1\right]$. Prospective passengers with somewhat lower values of $\theta$ will travel second class. Let those values of $\theta$ be in the interval $\left[\theta_{2}, \theta_{1}\right]$. Prospective passengers with even lower values of $\theta$, i.e., those in the interval $\left[\theta_{3}, \theta_{2}\right]$, will go steerage, and the ones will the lowest willingness to pay, i.e., those with values of $\theta$ lower than $\theta_{3}$ will not travel at all. Denote the number of prospective passengers in the market by $M$. Given that quality has been scaled so that $\theta$ has a standard uniform distribution, the number of people traveling first class is $Q_{1}=M\left(1-\theta_{1}\right)$, the number going second class is $Q_{2}=M\left(\theta_{1}-\theta_{2}\right)$, while the number in steerage is $Q_{3}=M\left(\theta_{2}-\theta_{3}\right)$.

To complete the analytical part of the model, we need only pin down $\theta_{1}, \theta_{2}$, and $\theta_{3}$. The first of these values is the lower bound of the interval of consumers who choose first class 
service over second class service. A passenger with $\theta=\theta_{1}$ is indifferent between these two classes of service, i.e., $\theta_{1} x_{1}-P_{1}=\theta_{1} x_{2}-P_{2}$. Solving for $\theta_{1}$ we obtain

$$
\theta_{1}=\frac{P_{1}-P_{2}}{x_{1}-x_{2}}
$$

Similarly, a passenger with $\theta=\theta_{2}$ is indifferent between traveling second class and steerage, i.e., $\theta_{2} x_{2}-P_{2}=\theta_{2} x_{3}-P_{3}$. Solving for $\theta_{2}$ we obtain

$$
\theta_{2}=\frac{P_{2}-P_{3}}{x_{2}-x_{3}}
$$

Finally, a prospective passenger with $\theta=\theta_{3}$ is indifferent between traveling steerage and not traveling at all, which yields zero surplus, i.e., $\theta_{3} x_{3}-P_{3}=0$. Solving for $\theta_{3}$ yields

$$
\theta_{3}=\frac{P_{3}}{x_{3}}
$$

Therefore, the analytic expressions for passenger volume as a function of prices and quality levels are given by

$$
\begin{aligned}
& Q_{1}=M\left(1-\frac{P_{1}-P_{2}}{x_{1}-x_{2}}\right) \\
& Q_{2}=M\left(\frac{P_{1}-P_{2}}{x_{1}-x_{2}}-\frac{P_{2}-P_{3}}{x_{2}-x_{3}}\right) \\
& Q_{3}=M\left(\frac{P_{2}-P_{3}}{x_{2}-x_{3}}-\frac{P_{3}}{x_{3}}\right)
\end{aligned}
$$

for first class, second class, and steerage, respectively. We later use these expressions in our quantitative exercise where we combine them with our regression estimates and some price data. Before this, however, we use the framework to infer substitution between classes of service. 
COLLUSION-INDUCED SUBSTITUTION BETWEEN CABIN AND STEERAGE AND

\section{EFFECTS ON MIGRANTS VERSUS TOURISTS}

The estimates reported in Table 3 can be used, in conjunction with our simple model, to construct counterfactual flows in the absence of collusive activity, i.e., to calculate the effects of collusion by chosen class of service when the market is competitive. In our model, consumers are put into four bins on the basis of the willingness to pay for quality of cabin service. Changes in prices of the three classes will shift the willingness to pay cut-offs separating the bins, but consumers switch at most one category up or down the quality ladder (as long as changes in relative prices are not too large). This key insight allows us to compute the counterfactual flows by class of service.

In Table 7 we present the substitutions and displacements of passengers between classes that the econometric estimates imply, averaged over the period of cartel operation. This table has two panels, each corresponding to groups of three regressions (one for each class) listed in Table 3. We describe carefully the construction of the top panel; the other is constructed similarly. This panel corresponds to westbound flows and computes the effect of collusion over the periods of normally operating cartels. We start by inserting the number of observations that correspond to this period for each of the classes of service, excluding those that involve Scandinavia (the only route for which collusion in steerage was not accompanied by collusion in cabin service). There are 139 observations with positive westbound first class flows during normal cartel operation, 145 observations with positive second class flows, and 151 with positive third class flows. The difference in observations across passenger classes is a function of the accommodations available in the ships on each route. We compute the total number of passengers that traveled in each class during this period, as reported in our data. Then, we insert in Table 7 the flows per quarter per 
route for each of the classes, right above the corresponding number of observations: 4,763 for first class, 8,172 for second class, and 33,297 for third class. ${ }^{35}$ These are based on actual data.

We now describe the computation of counterfactual flows, based on these data and on parameter estimates. We calculate the counterfactual flows for each class and observation by dividing actual flows by $e^{\alpha_{c}}$ where $\alpha_{c}$ is the sum of the cartel agreement and normal cartel operation coefficients for service $c$. The total flows for each class is the sum of these flows over all observations of positive flows for service $c$. We insert on the right-most column of the first panel of Table 7, under the heading "Total," the average per route and per quarter of these flows. ${ }^{36}$ Since the number of actual first class passengers (always per route-quarter) is smaller than the counterfactual number, we attribute on the basis of the model that all 4,763 passengers that traveled first class under the collusive regime would have traveled first class in the absence of collusion. The remaining 4,877-4,763=113 passengers who would have travelled first class in the absence of collusion, traveled second class following collusion. The number of passengers traveling second class under collusion consists of these 113 passengers plus an additional 8,059 passengers, yielding the observed number of 8,172 . Since in the counterfactual 8,175 passengers travel second class, $8,175-8,059=116$ passengers who would have traveled second class under competition get displaced to steerage by collusion. Finally, moving to steerage, we see that without collusion 46,815 passengers would have traveled per route-quarter, while only 33,297 actually did travel in the presence of collusion. Thus, the number who was displaced and did not travel at all is $46,815-33,297+117=13,635$. The other three panels were constructed in a similar manner. In sum, there is only limited downgrading from first to second or second to third class when cartels raise fares, though these shifts are more noticeable for eastbound traffic. Nonetheless, positive shifts from cabin to steerage imply that the displacement of steerage 
passengers is larger than appears from the regression coefficients in the third class specifications. This is because the regression coefficients for steerage give the reduction in the number of people who travel steerage, not how many of the people who would have traveled in steerage are displaced from traveling at all.

The figures in Table 7 permit us to also ascertain the relative cartel impact on permanent immigrants to North America contrasted with the impact on short-term migrants and tourists. The difference between westbound and eastbound flows is net migration to North America. The eastbound flows are equal to the round-trip tourist flows plus the reverse migrants. Note that the total gross westbound migration (the figures recorded in Ellis Island) is the sum of the net westbound migration plus the migrants who eventually return. We cannot separate reverse migrants from tourists in eastbound flows, unless we make the (somewhat strong but not implausible) assumption that tourists were all traveling cabin class and reverse migrants were all traveling steerage. We first provide an analysis without this assumption, and then provide an analysis with it. The net westbound flows in the absence of collusion are 24,757 people per route-quarter; under collusion this number drops to 22,150 , a $10.5 \%$ decline. The eastbound flows under competition are 35,110 people per route-quarter, which drop to 24,083 under collusion, a $31.4 \%$ decline. Thus, the decline in tourist and short-term (round-trip) migration is steeper than the decline in permanent one-way migration. This is expected, since the permanent migrants should be less price-sensitive than the tourists and shorter-term migrants (given the relatively large present value of lifetime earnings). If in addition we assume that tourists consisted of the cabin class eastbound passengers, we can separate the tourists from the shortterm migrants. Under this assumption, collusion reduces tourist traffic from 10,898 to 9,533 per route-quarter, or $12.5 \%$, and reduces short-term (round trip) migration from 24,212 to 14,550, or 
$39.9 \%$. Total gross westbound migration is reduced from 48,969 to 36,699 per route-quarter, or by $25.1 \%$. This figure is similar to that in Deltas, Sicotte, and Tomczak (2008), and which was arrived by the assumption that all westbound steerage passengers were migrants. The "refinement" in this analysis suggests that the reduction was disproportionately felt by short-term migrants rather than by permanent immigrants, and that the reduction in tourist traffic is intermediate of that of the two types of migrants.

QUANTITATIVE ANALYSIS USING THE ANALYTICAL MODEL AND AVAILABLE

\section{PASSENGER FARES}

We now proceed to the calibration of the analytical model of demand. Equations (1a), (1b), and (1c) yield the passenger volume by class as a function of prices, quality, and market size. We fit the model separately to eastbound and westbound flows for normally operating cartels. We plug into each of the three equations the flows by class and the average prices, which we summarize in Table 8 . We replicate the system of equations for the counterfactual non-collusive regime, and plug into each of the equations the counterfactual flows under non-collusion along with the non-collusive prices (also summarized in Table 8). The quality of steerage is assumed to be constant across the collusive and non-collusive regimes, but we allow the quality of cabin service to vary because firms may have enhanced quality under collusion given the inability to compete on price. Finally, given that the regression results are meant to yield contemporaneous counterfactual flows, we assume that the number of potential travelers is the same for the collusive and non-collusive states. These choices lead to the following system of equations:

$$
Q_{1}^{\text {cartel }}=M\left(1-\frac{P_{1}^{\text {cartel }}-P_{2}^{\text {cartel }}}{x_{1}^{\text {cartel }}-x_{2}^{\text {cartel }}}\right)
$$




$$
\begin{aligned}
& Q_{2}^{\text {cartel }}=M\left(\frac{P_{1}^{\text {cartel }}-P_{2}^{\text {cartel }}}{x_{1}^{c \text { rtel }}-x_{2}^{\text {cartel }}}-\frac{P_{2}^{\text {cartel }}-P_{3}^{\text {cartel }}}{x_{2}^{\text {cartel }}-x_{3}}\right) \\
& Q_{3}^{\text {cartel }}=M\left(\frac{P_{2}^{\text {cartel }}-P_{3}^{\text {cartel }}}{x_{2}^{\text {cartel }}-x_{3}}-\frac{P_{3}^{\text {cartel }}}{x_{3}}\right) \\
& Q_{1}^{\text {comp }}=M\left(1-\frac{P_{1}^{\text {comp }}-P_{2}^{\text {comp }}}{x_{1}^{\text {comp }}-x_{2}^{\text {comp }}}\right) \\
& Q_{2}^{\text {comp }}=M\left(\frac{P_{1}^{\text {comp }}-P_{2}^{\text {comp }}}{x_{1}^{\text {comp }}-x_{2}^{\text {comp }}}-\frac{P_{2}^{\text {comp }}-P_{3}^{\text {comp }}}{x_{2}^{\text {comp }}-x_{3}}\right) \\
& Q_{3}^{\text {comp }}=M\left(\frac{P_{2}^{\text {comp }}-P_{3}^{\text {comp }}}{x_{2}^{\text {comp }}-x_{3}}-\frac{P_{3}^{\text {comp }}}{x_{3}}\right)
\end{aligned}
$$

where the first three equations refer to the cartel regime (with the corresponding variables and data labeled with the superscript "cartel"), and the second group of three equations refer to the competitive counterfactual (with the corresponding variables and data labeled with the superscript "comp"). Observe that this is a system of six equations with six unknowns. Solving for the quality levels and the size of the market we obtain the estimates of the unknown parameters, which are reported in Table 8 . Since this is an extremely stylized model, we take these estimates as indicative only. However, they do provide a basis for discussion and evaluation of our interpretation that the price and quantity changes were indeed consistent with profit maximizing collusive agreements. ${ }^{37}$ 
THE COLLUSIVE REGIME: MODEL PREDICTION, OBSERVED OUTCOMES AND

\section{EVALUATION}

How would a perfectly functioning cartel set prices when faced with the consumer demand structure developed above? Such a cartel would set prices to maximize profits taking into consideration that the number of tickets for each of the three classes is given by equations (1a) to (1c). The profit function of the cartel is

$$
\Pi=\left(P_{1}-c_{1}\right) Q_{1}+\left(P_{2}-c_{2}\right) Q_{2}+\left(P_{3}-c_{3}\right) Q_{3}
$$

Substituting from equations (1a) to (1c), we obtain

$$
\Pi=M\left[\left(P_{1}-c_{1}\right)\left(1-\frac{P_{1}-P_{2}}{x_{1}-x_{2}}\right)+\left(P_{2}-c_{2}\right)\left(\frac{P_{1}-P_{2}}{x_{1}-x_{2}}-\frac{P_{2}-P_{3}}{x_{2}-x_{3}}\right)+\left(P_{3}-c_{3}\right)\left(\frac{P_{2}-P_{3}}{x_{2}-x_{3}}-\frac{P_{3}}{x_{3}}\right)\right]
$$

The first order conditions of profit maximization with respect to the three prices are very messy and we omit them. But the expressions for the optimal prices are rather simple:

$$
P_{1}^{*}=\frac{x_{1}+c_{1}}{2} \quad P_{2}^{*}=\frac{x_{2}+c_{2}}{2} \quad P_{3}^{*}=\frac{x_{3}+c_{3}}{2}
$$

Though the expressions for each of the three classes of service are identical, one can see that the gap between prices and marginal cost is proportionately greater for the classes where quality is high relative to costs. To obtain numerical predictions for prices under collusion, we substitute estimates of quality and marginal cost. With regards to costs, we assume that in the competitive regime, the firms set prices equal to marginal costs. This may not be fully accurate, but it is not a bad approximation except for westbound flows at peak seasons. With regards to quality levels, we use our estimates of quality under the competitive regime (using average quality across both regimes does not materially affect our conclusions). The profit maximizing prices of the cartel predicted by the model, reported in Table 8 , are uniformly higher than the observed ones. It is 
instructive to contrast the figures for cabin versus steerage, given that first and second class services have low volumes and are more similar. For cabin service (first and second class), the average price increase predicted by the model is $49 \%$ eastbound and $32 \%$ westbound versus the observed figures of $31.5 \%$ and $15 \%$, respectively. For steerage the increase predicted by the model is $93 \%$ eastbound and $60 \%$ westbound versus the observed figures of $58 \%$ and $31 \%$. Notice that even though the model predicts larger price increases, the relative price increases are very close: for both cabin and steerage the observed price increase is half to three-fifths of the predicted increase for either direction. Thus, the model does a great job in theoretically supporting the observation that cabin services prices increased by more than steerage prices, but suggests that monopoly prices are higher than those the cartel chose to charge.

There are, though, some good reasons why this is the case. First, the model omits any differentiation between the firms. Such differentiation would reduce the predicted percentage increases from collusion. In fact, in the extreme case that the firms are completely differentiated (e.g., they operate in distinct markets), collusion would not affect prices at all since the firms are monopolists to begin with. Second, the model assumes that collusion results in monopoly pricing, i.e., that there are no cartel enforcement problems. In reality, all cartels face enforcement problems, and may choose prices lower than the monopoly level to reduce the incentive to cheat. Finally, the model does not incorporate the possibility that much of the travel was "round-trip." When some travelers buy return tickets, raising the price of the one-way ticket reduces the willingness to pay for the return leg. This does not affect the price under competition, since it is set at marginal cost, but reduces the optimal monopoly price. Thus, cartel prices will not be as high. It is quite plausible that these factors account for the discrepancy between the predicted and 
actual price increases. By contrast, if the predicted prices had been lower than the observed ones, then the model would have been harder to reconcile with the data.

\section{THE EFFECT OF COLLUSION ON IMMIGRANT "QUALITY" AND CONCLUDING REMARKS}

The analysis in the previous section argues that potential steerage passengers with the lowest willingness to pay were those who were deterred from traveling. Westbound, these passengers consist mostly of immigrants with low incomes or savings, or who had relatives in the United States with relatively low incomes or savings. Given the magnitude of the estimated impact of collusion on flows, especially after accounting for substitution across classes of service, it is possible that the composition of migrants to the United States was materially affected, and in particular, that immigrants with the lowest "quality" represented a smaller fraction of U.S. immigration during collusive periods. ${ }^{38}$ We next present evidence that collusion indeed reduced the fraction of immigrants who were illiterate and increased the funds they brought with them, thereby materially affecting the composition of U.S. immigrants along important human capital and financial characteristics. The latter finding is remarkable given that immigrants traveling on collusive routes paid higher fares, but still ended up with larger available funds upon arrival.

The Annual Reports of the Commissioner-General of Immigration of the United States provide the number of passengers by ethnicity and fiscal year (July 1 - June 30) who could not read or write, and the total number of immigrants by ethnicity and age category (under 14,

between 14 and 44, and over 44). ${ }^{39}$ From these data, we calculate the percentage of immigrants 14 and older who were illiterate by ethnicity and year. The data distinguishes among 29 ethnicities from Europe, a number that exceeds the number of independent states at that time 
period (and greatly exceeds the number of routes). This richness of the data is an important advantage for isolating the effects of cartelization in migrant literacy, as it allows us to control for ethnic composition effects. With literacy rates differing substantially across ethnic groups, changes in the ethnic composition of immigrants for any of a large number of reasons would affect immigrant literacy. With our data representing a panel of literacy rates for each of 29 European ethnicities, we can identify the effect of collusion on the literacy rate of migrants that traverse the Atlantic via cartelized routes controlling for each ethnicity's underlying literacy rate. These effects are clearly under-estimates, since some of the cartel effects on literacy rates manifest themselves through changes in the ethnic composition of immigrants from poorer and less literate ethnicities to richer and more literate ones. We thus also provide estimates that do not employ ethnicity fixed effects, which might be considered as upper bounds of the cartels' impact.

As a starting point, we assign each ethnicity to the shipping route on which they were most likely to travel - Italians to the Mediterranean, Irish to the United Kingdom, etc. We then regress the percentage illiterate by ethnicity-year on the cartel status in that year for each ethnicity's "assigned" route and on a set of covariates. The results are reported in Table 9, Panel A. The first model is the richest, controlling for an annual trend, the dummy for the big recession of 1908, and for a set of ethnicity fixed effects. The observations are weighted by the total number of immigrants of the corresponding ethnicity over the entire time period, so that small ethnic groups do not have a disproportionate impact on the estimates. Cartel operation reduces illiteracy rates by 1.3 percentage points. This figure represents a substantial fraction of the average illiteracy rate, which for this sample stands at around $25 \%$. The results are stronger if we do not use ethnicity weights in the regression (Model 2). Dropping the 1908 dummy has no 
impact on the ethnicity-weighted estimates (Model 3). These estimated effects are conservative because they represent the shift toward more educated immigrants within each ethnicity. However, it stands to reason that the higher collusive prices led to reduction in the immigration flows from poorer and less educated ethnicities. If that were true, dropping the ethnicity fixed effects would lead to substantially larger collusion effects. This is indeed the case, as can be seen from Model 4. The effect of collusion on illiteracy is a whopping 13 percentage points, suggesting that most of the impact was coming through reallocation of immigration across ethnicities. Dropping all covariates and weights, and estimating the simplest naïve treatment model, still yields a huge effect (model 5).

To complement this analysis, we obtain from the same source information on the average funds, in dollars, that immigrants showed upon arrival to the immigration officer. Though many immigrants did not reveal the full extent of funds at their disposal, this measure is an important proxy of the financial assets of the immigrants. ${ }^{40}$ We estimate the same set of regressions as those reported in Panel A of Table 9, but using instead as the dependent variable the average money per person by ethnic group. The regression results are reported in Panel B. Our base specification, Model 1, shows that collusion resulted in immigrants with, on average, 2.25 more dollars per person. This represents an approximately $10 \%$ increase in financial resources. Contrary to illiteracy rates, there is a positive trend in these financial resources, and the effect of the 1908 dummy is negative. The significance of the cartel effect increases from $10 \%$ to $5 \%$ with the exclusion of the 1908 dummy (model 3), but significance is narrowly lost when the observations are not ethnicity weighted (model 2). As with the literacy regressions, dropping the ethnicity dummies leads to substantially larger collusion effects: clearly, much of the impact of higher fare prices operated through a rebalancing of the immigration flows towards ethnic groups 
that had greater funds and could afford the higher fares. These findings, taken together, support the view that as cartels raised fares, the composition of westbound migrant traffic shifted toward those with greater human and financial capital.

This study showed that periods of collusion result in substantial reductions in passenger flows. Even though we control for route unobserved heterogeneity and economic conditions as best as possible, one might still be concerned that other factors were at play and that collusion was not the driving force. Our price data confirm that collusive periods were indeed associated with higher fares. We then verified that these higher fares were at a plausible level for a profitmaximizing cartel, by using a stylized model of vertical differentiation in a three-tiered product which we fit to the flow and price estimates. The model yields estimates with reasonable values for willingness to pay for each cabin class level and for market size. Moreover, the model yields predictions on the optimal cartel prices for each class of service. These estimates confirm that cartel prices would increase more for steerage than for cabin service, as observed in the data. The observed price increases are a bit over half of the predicted ones, which is not surprising given that the model omits (by necessity) three elements present in the real world, the incorporation of each one of which would reduce the optimal cartel price. Consistent with the theoretical analysis, we have also presented evidence that the steerage passengers with the least willingness or ability to pay were those most displaced by the cartel operations. This is manifested by a reduction in the illiteracy rate of immigrants from Europe into the United States and an increase in the funds they brought with them. In brief, cartels hurt primarily the economically disadvantaged and kept low income and low education Europeans from migrating to North America. 


\section{REFERENCES}

BAINES, DudLEY. 1994. European Emigration, 1815-1930: Looking at the Emigration Decision Again. The Economic History Review, 47: 525-544.

Bandiera, Oriana. Imran Rasul and Martina Viarengo. 2013. The Making of Modern America: Migratory Flows in the Age of Mass Migration. Journal of Development Economics 102: $23-47$.

BRINKMANN, TOBIAS. 2008. Travelling with Ballin: The Impact of American Immigration Policies on Jewish Transmigration within Central Europe, 1880-1914. International Review of Social History 53: 459-84.

Bryan, Gharad, Shyamal Chowdhury, And Ahmed Mushfiq MobaraK. 2014.

Underinvestment in a Profitable Technology: The Case of Seasonal Migration in Bangladesh. Econometrica 82: 1671-748.

Clay, Karen and Werner Troesken. 2003. Further Tests of Static Oligopoly Theory:

Evidence from Distilling, 1881-1900. Journal of Industrial Economics 51: 151-66.

Clay, Karen and Werner Troesken. 2002. Strategic Behavior in Whiskey Distilling, 18871895. Journal of Economic History 62: 999-1023.

Cohn, Raymond. 2009. Mass Migration Under Sail: European Immigration to the Antebellum United States. Cambridge: Cambridge University Press.

Cohn, Raymond And Simone Wegge. 2015. Overseas Passenger Fares and Emigration from Germany in the Mid-Nineteenth Century. Unpublished paper, Illinois State University. Connor, John And Yuliya Bolotova. 2006. Cartel Overcharges: Survey and Meta-Analysis. 
International Journal of Industrial Organization 24: 1109-37.

Deltas, George, Richard Sicotte and Peter Tomczak. 2008. Passenger Shipping Cartels and Their Effect on Trans-Atlantic Migration. Review of Economics and Statistics 90: 119-33.

Dupont, Brandon, AlKa Gandhi, And Thomas Weiss. 2012. The Long Term Rise in Overseas Travel by Americans, 1820-2000. Economic History Review 65: 144-67.

Dupont, Brandon And Thomas Weiss. 2013. Variability in Overseas Travel by Americans, 1820-2000. Cliometrica 7: 319-39.

FeldenKIRChEN, WiLfried. 1992. Competition Policy in Germany. Business and Economic History 21: 257-69.

FEys, TORSTEN. 2013. The Battle for Migrants: The Introduction of Steamshipping on the North Atlantic and Its Impact on the European Exodus. St. John's, Newfoundland: International Maritime Economic History Association.

Feys, Torsten. 2008. Prepaid Tickets to the New World: The New York Continental Conference and Trans-Atlantic Steerage Fares, 1885-1895. Revista de Historia Económica 26: 173-204.

Genesove, David And Wallace Mullin. 2001. Rules, Communication and Collusion: Narrative Evidence from the Sugar Institute Case. American Economic Review 91: 379-98.

Grogger, JeFFrey and Gordon Hanson. 2011. Income Maximization and the Selection and Sorting of International Migrants. Journal of Development Economics 95: 42-57.

Grossman, Peter. 2004. Why One Cartel Fails and Another Endures: The Joint Executive Committee and the Railroad Express. In How Cartels Endure and How They Fail, edited by Peter Grossman. Northampton, MA: Edward Elgar. 
Hatton, Timothy and Jeffrey Williamson. 1998. The Age of Mass Migration: Causes and Economic Impact. New York: Oxford University Press.

Hatton, Timothy AND JefFrey WiLLiAmson. 2006. International Migration in the Long Run: Positive Selection, Negative Selection, and Policy. In Federico Foders and Rolf Langhammer, Editors. Labor Mobility and the World Economy. Berlin . Heidelberg: Springer-Verlag Hourwich, IsAaC. 1911. The Economic Aspects of Immigration. Political Science Quarterly 26: $615-42$.

Hyde, Francis. 1975. Cunard and the North Atlantic 1840-1973: A History of Shipping and Financial Management. London: The MacMillan Press.

KeEling, Drew. 2005. The Business of Trans-Atlantic Migration between Europe and the United States. Ph.D. dissertation. University of California, Berkeley.

KeEling, Drew. 2007. Costs, Risks, and Migration Networks between Europe and the United States, 1900-1914. Research in Maritime History 33: 113-73.

KeELING, Drew. 2008. The Voyage Abstracts of the Cunard Line as a Source of Transatlantic Passenger Fares. Business Archives 96: 15-36.

KeEling, Drew. 2012. The Business of Trans-Atlantic Migration between Europe and the United States. Zurich: Chronos.

KILliCK, JOHN. 2014. Transatlantic Steerage Fares, British and Irish Migration, and Return Migration, 1815-1860. The Economic History Review 67: 170-91.

Kleemans, MARIEKE. 2015. Migration Choice under Risk and Liquidity Constraints. Unpublished paper, University of California, Berkeley.

Lamoreaux, NaOmi. 1988. The Great Merger Movement in American Business, 1895-1904. 
New York: Cambridge University Press.

Lebergott, Stanley. 1964. Manpower in Economic Growth. New York: McGraw-Hill.

LeVenstein, Margaret. 1996. Do Price Wars Facilitate Collusion? A Study of the Bromine Cartel before World War I. Explorations in Economic History 33: 107-37.

LeVenstein, Margaret. 1995. Mass Production Conquers the Pool: Firm Organization and the Nature of Competition in the Nineteenth Century. Journal of Economic History 55: 575-611.

LeVenstein, Margaret And VAlerie Suslow. 2006. "What Determines Cartel Success?

Journal of Economic Literature 44: 43-95.

LeVenstein, Margaret And Valerie Suslow. 2014. Cartels and Collusion: Empirical Evidence. In The Oxford Handbook of International Antitrust Economics 2, edited by Roger Blair and D. Daniel Sokol. Oxford, Oxford University Press.

Maddison, Angus. 1982. Phases of Capitalist Development. Oxford: Oxford University Press.

MARX, DANIEL. 1953. International Shipping Cartels: A Study of Industrial Self-Regulation by Shipping Conferences. Princeton: Princeton University Press.

Magee, Gary B. And Andrew S. Thompson. 2006. The Global and the Local: Explaining Migrant Remittance Flows in the English-Speaking World, 1880-1914. The Journal of Economic History 66: 177-202.

MEARS, Eliot. 1923. Financial Aspects of American Immigration. The Economic Journal 33: $332-42$.

Molloy, Robert. 1940. Application of the Anti-Trust Laws to Extraterritorial Conspiracies. Yale Law Journal 49: 1312-9. 
MÜRKEN, ERICH. 1922. Die grossen transatlantischen Linienreederei-Verbande, Pools und Interessengemeinschaften. Jena, Germany: Verlag von Gustav Fischer.

Mussa, Michael And SHerwin Rosen. 1978. Monopoly and Product Quality. Journal of Economic Theory 18: 301-17.

New York. COMmission OF Immigration. 1909. Report of the Commission of Immigration of the State of New York. Document No. 29.

O’Rourke, Kevin AND JeFFrey WiLliamson. 1999. Globalization and History: The Evolution of a Nineteenth-Century Atlantic Economy. Cambridge, MA: The MIT Press.

SCIENTIFIC AmERICAN. 1910. Scientific American Handbook of Travel. New York: Munn and Co. SCOtT Morton, Fiona. 1997. Entry and Predation: British Shipping Cartels 1879-1929. Journal of Economics \& Management Strategy 6: 679-724.

Sicotte, Richard. 1999. Economic Crisis and Political Response: The Political Economy of the Shipping Act of 1916. The Journal of Economic History 59: 861-84.

SteVEns, W. H. S. 1914. The Administration and Enforcement of Steamship Conferences and Agreements. Annals of the American Academy of Political and Social Science 55: 112-43.

Stigler, George. 1964. A Theory of Oligopoly. Journal of Political Economy 72: 44-61.

SZAJKOWSKI, Zosa. 1977. Sufferings of Jewish Emigrants to America in Transit through Germany. Jewish Social Studies 39: 105-16.

TiRole, Jean. 1988. The Theory of Industrial Organization, Cambridge, MA: The MIT Press. United States. Department of Commerce. Bureau of the Census. 1975. Historical Statistics of the United States. Washington: GPO. 
United States. House of Representatives. Committee on Merchant Marine AND

FISHERIES. 1914. Steamship Agreements and Affiliations in the American Foreign and Domestic Trade. 63rd Congress, 2nd Session. Document No. 805.

United States. Department of COMMERCE AND Labor. Bureau of IMMigration AND NAtURAlizATION. 1912. Annual Report of the Commissioner-General of Immigration to the Secretary of Commerce and Labor for the Fiscal Year ended June 30. Washington: GPO.

United States. Immigration Commission. 1911. Reports of the Immigration Commission. Statistical Review of Immigration, 1820-1910. 61st Congress, 3rd Session. Document No. 756. UNITED STATES V. HAMBURG-AMERICAN LINE ET AL., 216 Fed. 971 (1914). Evidence and Briefs.

UNITED STATES V. HAMBURG AMERICAN CO., ET AL., 239 U.S. 466 (1916). Evidence and Briefs.

WiLliamson, JEFFREy. 1995. The Evolution of Global Labor Markets since 1830: Background Evidence and Hypotheses. Explorations in Economic History 32: 141-96.

\footnotetext{
${ }^{1}$ In studies focusing on shipping and migration in the nineteenth century, Cohn (2009) believes ocean fares may have influenced passenger flows, and Killick (2014), relying on a series of fare data from 1815-1860, argues that a decline in fares stimulated migration during that period (see also Feys 2013). Keeling (2012) has written that he finds it hard to believe that migratory flows were sensitive to fluctuations in rates. None of these studies, however, carry out econometric investigations.
} 
${ }^{2}$ However, many second class passengers were migrants (Keeling 2012; Bandiera, Rasul and Viarengo 2013).

${ }^{3}$ Most eastbound travelers were reverse migrants. In what follows, we provide some evidence that transient migrants, who constituted this reverse migration, were the most affect by the collusion.

${ }^{4}$ This presumption was fortuitous for our study, because the cartel firms were sufficiently confident in the legality of their combination, that they kept extensive cartel records in their offices in New York - records that later were subpoenaed and preserved in legal archives. 5 A comprehensive list of estimated cartel price effects of varying fidelity is in Connor and Bolotova (2006).

${ }^{6}$ Cohn and Wegge (2015), whose data are for the mid-19th century, discuss the likely impact of high ocean fares on the observed positive selection of migrants from Germany.

${ }^{7}$ Until that time, the presumption was that international shipping cartels were legal in the United States. Furthermore, British law did not prohibit shipping cartels, although British courts would not enforce shipping cartel agreements under contract law, as was done in Germany. United States v. Hamburg-Amerikanische Packet Fahrt Actien Gesellschaft, 200 F. 806 (SDNY, 1911), 216 F. 971 (SDNY, 1914), 239 U.S. 466 (1916); Mogul Steamship Co. Ltd. v McGregor, Gow and Co. LR 21 QBD 544 (1888), 23 QBD 598 (1889), AC 25 House of Lords (1892); Feldenkirchen (1992).

${ }^{8}$ Fares were quoted in the currencies of the countries in which they were sold. Cartel agreements frequently specified rates of exchange between currencies, which was simple during 
this period due to the near universal usage of fixed exchange rate regimes. The Allan Line fares refer to the United Kingdom to United States route.

${ }^{9}$ Feys 2013, 89; The Immigration Commission of the State of New York 1909, 38, reports that $60-80 \%$ of all tickets sold by steamship agents in New York State were prepaid tickets; Mears 1923, 335, opines that 40\% “is a conservative guess." See also Baines, 1994 and Magee and Thompson, 2006.

${ }^{10}$ See the discussion in Feys 2008, as well as the testimony of agents in United States v. Hamburg-American, the Report of the Commission of Immigration of the State of New York, pp. 38-40, and extant copies of prepaid ticket receipts (Gjenvick-Gjonvik Archives, www.gjenvick.com).

${ }^{11}$ New York Times, March 15, 1907, p. 16; New York Times, April 21, 1908, p. 5; Anchor Line brochure: "Special Attractions for Excursion Season 1911," from www.gjenvick.com; "The Scientific American Handbook of Travel" from openlibrary.org; Dupont, Gandhi and Weiss. 12 These included the North Atlantic Steamship Lines Agreement (Hamburg-American, North German Lloyd, Holland-America, and Red Star) of 1892; side agreements of those lines with Cie. Generale Transatlantique, British lines for their continental passengers, and Canadian Pacific Railway, each reached at different dates; Agreement AA of 1908; the Mediterranean Steerage Agreement of 1909, and its side agreements with Greek Lines and for passengers from Fiume and Trieste in Austria-Hungary.

${ }^{13}$ For examples, see Petitioner's Exhibits 953, 957, 1148, 1379, 1567, 1778, and Defendant's Exhibit 134. 952: Cable from cartel Secretary to member firms of Agreement AA, "Statistical Returns," Jena, April 23, 1908. 953: Cable from Secretary to member firms of Agreement AA, 
“Weekly Statistics, Eastbound," Jena, April 23, 1908. 957: Cable from Secretary to member firms, "Monthly Statements," Jena, April 25, 1908. 1148: Cable from Secretary to member firms of Agreement AA, “Communications to Press," Jena, November 12, 1908. 1379: Cable from Secretary to member firms of Agreement AA, untitled, Jena, July 6, 1909. 1567: Cable from Secretary to member firms of Agreement AA, "Payments for April," Jena, May 9, 1910. 1778: Cable from Passenger Department, White Star Line, Liverpool, to Passenger Department, White Star Line, New York, "Minutes of Meeting held at Paris, $25^{\text {th }}$ March, 09, Hotel Meurice. March 27, 1909. Defendant's Exhibit 134: Cable from Secretary to member firms of Atlantic Conference, "Monthly Adjustment Payments with the Scandinavian American Line,” Jena, July 7, 1909.

${ }^{14}$ Our passenger flow data include those carried on both cartel and non-cartel firms.

${ }^{15}$ As an epilogue to the case, we note that passenger shipping on the North Atlantic was cartelized until the industry ceased to exist in the early 1970s. Liner shipping among freight carriers also has been frequently cartelized, although in recent years the market structure has undergone some changes. Other industries with high fixed costs, uncertain demand, and frequent overcapacity, where marginal cost pricing might lead to losses, have had a higher incidence of collusion. This is consistent with standard models of cartels. Examples of such industries include railroads, steel and cement. See Marx (1953) and Levenstein and Suslow (2006). ${ }^{16}$ A quarterly frequency captures the formation and dissolution dates of the cartel agreements and uses the full variation of the economic time series, some of which are at higher than annual frequencies. It also permits us to lag key determinants of flows by two quarters to account for lags between the decision to travel and actual travel. Data at a finer partition introduces variation 
generated by unusual groupings of sailings just after or before the beginning of a particular month. This is particularly problematic for routes with only a few voyages per month. In our classification, Britain includes all ports in Britain and Ireland, Scandinavia includes all ports of Denmark, Norway and Sweden, North France includes the ports in the French Atlantic, Rhine includes all other ports of northern Europe, while Mediterranean includes all ports of Southern Europe and Asia Minor.

${ }^{17}$ For example, although there was sporadic service from Libau (in present Latvia), the great majority of passengers from the Russian Empire traveled through Germany (Brinkmann, 2008). This suggests including Germany and Russia in the same route. Similarly, although there were some passengers from Mediterranean countries that traveled from northern Europe and Scandinavians that traveled through Britain, there was consistent direct service from these regions to the United States, suggesting that they should form separate routes. Also, the overwhelming majority of passengers to the United States traveled in and out of New York, though Boston, Philadelphia and Baltimore also had direct service. There were virtually no direct voyages to New Orleans or other ports. This suggests aggregating all U.S. ports into a single origin and destination.

18 The variable AGREEMENT $\mathrm{jt}_{\mathrm{jt}}$ is referred to as "Cartel Agreement" in the Tables; NORMAL $\mathrm{j}_{\mathrm{jt}}$ is referred to as "Normal Cartel Operation."

${ }^{19}$ See chapter 3 of Hatton and Williamson (1998), chapter 7 of O'Rourke and Williamson (1999) and references therein for discussion of the link between economic conditions and transatlantic travel and migration. 
${ }^{20}$ The wage and GDP data (described later in this paragraph) are proxies because we do not have information all countries. For example, we do not have a GDP or wage series for Russia or for any Balkan state.

${ }^{21}$ We were unable to identify employment data for Canada. Therefore, for some specifications we use the U.S. series as a proxy, while for others we set the employment-related variable to zero for the Canadian routes.

${ }^{22}$ There was movement of migrants away from the port of arrival. But from the point of view of our analysis, the only relevant movement is between the United States and Canada. Any such movement would attenuate our estimates of the importance of destination economic conditions for westbound flows. This is a minor issue given that the economic conditions are used as auxiliary controls and are not the main parameters of interest.

${ }^{23}$ For the short period that we study, route fixed effects effectively subsume the level of population and full-employment GDP on route pairs, i.e., they generalize the "gravity" models found in some migration studies.

${ }^{24}$ For brevity, we do not report the variance regressions. The dependent variable is in logs because all the explanatory variables are expected to have a proportional impact on flows. This includes the cartel effects, which are of primary interest. Clearly their impact on flows is not invariant across all routes and times, but proportional to the respective baseline flows. The log specification drops all observations with zero flows. However, the amount of censoring is limited: approximately 6 percent for steerage and 14 for cabin service.

${ }^{25}$ The evidence on cartel formation and breakdown does not suggest any possible correlation between unobserved demand for travel and the cartel agreement variables conditional on the set 
of economic controls and the route fixed effects we use. Therefore, there is little (if any) need for an IV estimation strategy, which would also be difficult to implement and would carry its own pitfalls.

${ }^{26}$ In a robustness check we used year dummy variables, which effectively requires dropping all other economic controls since they are obtained at an annual frequency. However, the identifying power of this specification is extremely weak, given that most agreements start and terminate in the same year, and the second cartelization phase affected all routes. Thus, the estimates, though broadly consistent with our reported results, are based on limited information and are sometimes very imprecise.

${ }^{27}$ When we do not distinguish the periods of normal cartel operation from those when cartels were disrupted, we find no statistically significant effect of cartelization on either first or second class, while the predicted effect of collusion on steerage is strongly negative (more than $20 \%$ ). ${ }^{28}$ In section 7, we show that round trip travel was indeed more sensitive than one-way travel. Note that net westbound flows imply that there were many empty seats on the eastbound journey. This could be consistent with optimal pricing if the shipping firms could not perfectly price discriminate. In that case, filling the empty seats would have led to lower prices on the inframarginal seats, lowering total revenue.

${ }^{29}$ Column 2 in Table 3 of Deltas, Sicotte and Tomczak (2008) differs from column 3 in Table 3 of the current paper only in that the former distinguishes cartel agreements between Tight and Loose, while the later distinguishes them between normally operating or not. The two partitions are similar but not identical. All other specifications are completely different. 
30 Another possible margin for substitution is that cartelization of some routes may affect the migrants' choice of route. We investigate this by adding a variable that indicates whether a route is not cartelized in the presence of general cartelization in the remaining routes. If there were diversion from the cartelized to the non-cartelized routes, it would be picked up by that variable. It turns out that this variable is not significant in any of our base specifications, and is more often negative than positive. Thus, there is no evidence that there was substitution across routes, perhaps because the route structure is substantially aggregated.

${ }^{31}$ We have also performed the analysis at an annual frequency, by averaging the quarterly observations and re-estimating the models reported in Tables 3 and 4 . The cartel coefficients continue to be negative and of similar value and significance, except for the eastbound third class estimates that are now implausibly large (while still negative). However, aggregating the data to an annual frequency results in loss of information for two reasons. First, the cartel agreements do not start and end in January or December. About half of the agreement spells have start/end dates in the second or third quarters, resulting in cartel dummies that are not 0 or 1 . Second, using a quarterly frequency on flows permits us to use a two-quarter lag. Such a lag structure would be more difficult to envision in the context of an annual frequency.

32 We have examined data reported in Cohn and Wegge (2015), Feys (2008), DuPont, Gandhi and Weiss (2012), and Killick (2014). These were either overlapped with the data reported in Keeling or were not sufficient for regression analysis on their own.

${ }^{33}$ Combined with the parameter estimates of Table 3 , these price effects could also yield estimates of demand "elasticity" for each of the three classes. However, this "elasticity" is not based on the partial effect of own price change, but on the effects of joint price changes across 
all three classes, because price wars did not affect the price of only one class of service, but the prices of all classes. For these reason, these elasticities are not reported here, though their values are quite reasonable.

${ }^{34}$ Some evidence on the substitutability of cabin classes for marginal passengers was discussed in Section 2. White Star and North German Lloyd brochures also highlighted this substitutability (gjenvick.com). There is evidence from the press that such substitutions were in fact occurring. For example, the Wall Street Journal, on June 24, 1908 (p. 8), stated that eastward second class flows had increased in the first half of 1908 even though first class flows declined. "Local agents attribute the increase in the eastward second class movement to the fact that many whose financial resources were impaired by the late panic would not forego the annual trip to Europe and accordingly took less attractive accommodations."

${ }^{35}$ In calculating the average quarterly flows per route, we need a common denominator so that we can make appropriate comparisons. For this reason, we divided the total flows for each class by the number of observations with positive steerage flows (essentially inserting observations with zero flows for the other cabin classes when there were steerage passengers but no cabin passengers).

${ }^{36}$ As with the actual flows, the average is obtained by dividing by the number of observations with positive steerage flows.

${ }^{37}$ We make three observations based on the parameter estimates. Our first observation is that the quality of steerage measured by willingness to pay appears to not be much worse than that of second class service. This is not surprising, though, since each fare is essentially a composite of two goods: passage between Europe and North America, and the quality of accommodations. 
The first good is common to all classes of service, while the difference in the willingness to pay for the classes of service is attributed to the difference in the quality of accommodations. Our second observation is that the estimated quality of cabin service seems to be largely unaffected by collusion: that of first class went up somewhat, but that of second class was reduced a bit. The average quality increase under collusion is only about a sixth of the typical gap between any two classes of service. Our final observation is that the number of prospective travelers per quarter on the typical route is about 54,000 eastbound and 130,000 westbound. This is little over twice the number of travelers during the non-collusive periods (around 24,000 eastbound and 47,000 westbound). Our back-of-the-envelope framework suggests that a total collapse of steerage prices to zero would more than double the steady-state level of flows. This is certainly plausible.

${ }^{38}$ There is some anecdotal evidence for this. In the United States v. Hamburg-American court case, two of steamship company witnesses, Hermann Winter and Sidney Lister, argued that when fares were low, as during rate wars, there were large increases of undesirable, lower class immigrants. For a long run perspective on immigrant selection see Hatton and Williamson (2006).

${ }^{39}$ Data for 1898-1910 are from the Report of Immigration Commission, Statistical Review of Immigration, 1820-1910. Data for 1911 are from the Annual Report of the CommissionerGeneral of Immigration for the year 1910/1911.

40 A large fraction of immigrants declared no funds, which is unlikely to be the true state of their financial resources, unless they were being met by relatives or friends upon arrival. 
Table 1. Classification of Cartel Status by Direction of Travel and Cabin Class

\begin{tabular}{|c|c|c|c|c|c|c|c|c|c|c|}
\hline \multirow{2}{*}{ Year } & \multirow{2}{*}{ Quarter } & \multirow[b]{2}{*}{ GB <-> US } & \multirow[b]{2}{*}{ GB <-> Can } & \multicolumn{5}{|c|}{ Route } & \multirow[b]{2}{*}{ Rhine <- Can } & \multirow[b]{2}{*}{ Scand $<->$ US } \\
\hline & & & & From Medit & To Medit & $\mathrm{n}<->$ US & Rhine <-> US & Rhine -> Can & & \\
\hline \multirow{4}{*}{1899} & $\bar{T}$ & All Classes & 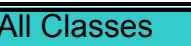 & All Classes & "All Classes & & "All Classes & "All Classes & & 3rd Class \\
\hline & II & All Classes & All Classes & All Classes & All Classes & & All Classes & All Classes & & 3rd Class \\
\hline & III & All Classes & All Classes & All Classes & All Classes & & All Classes & All Classes & & 3 rd Class \\
\hline & IV & All Classes & All Classes & All Classes & All Classes & & All Classes & All Classes & & 3rd Class \\
\hline \multirow{4}{*}{1900} & 1 & All Classes & All Classes & All Classes & All Classes & & All Classes & All Classes & & 3rd Class \\
\hline & II & All Classes & All Classes & All Classes & All Classes & & All Classes & All Classes & & 3rd Class \\
\hline & III & All Classes & All Classes & All Classes & All Classes & & All Classes & All Classes & & 3rd Class \\
\hline & IV & All Classes & All Classes & All Classes & All Classes & & All Classes & All Classes & & 3rd Class \\
\hline \multirow{4}{*}{1901} & I & All Classes & All Classes & All Classes & All Classes & & All Classes & All Classes & & 3rd Class \\
\hline & II & All Classes & All Classes & & All Classes & & All Classes & All Classes & & 3rd Class \\
\hline & III & All Classes & All Classes & & All Classes & & All Classes & All Classes & & 3rd Class \\
\hline & IV & All Classes & All Classes & & All Classes & & All Classes & All Classes & & 3rd Class \\
\hline \multirow{4}{*}{1902} & 1 & All Classes & All Classes & & All Classes & & All Classes & All Classes & & 3rd Class \\
\hline & II & All Classes & All Classes & & All Classes & & All Classes & All Classes & & 3rd Class \\
\hline & III & All Classes & All Classes & & All Classes & & All Classes & All Classes & & 3rd Class \\
\hline & IV & All Classes & All Classes & & All Classes & & All Classes & All Classes & & 3rd Class \\
\hline \multirow{3}{*}{1903} & 1 & All Classes & All Classes & & All Classes & All Classes & All Classes & All Classes & & 3rd Class \\
\hline & II & All Classes & All Classes & & All Classes & All Classes & All Classes & All Classes & & 3rd Class \\
\hline & III & All Classes & All Classes & & All Classes & All Classes & All Classes & All Classes & & 3rd Class \\
\hline \multirow[t]{2}{*}{1904} & $\begin{array}{c}\text { IV } \\
\text { I } \\
\text { II } \\
\text { III }\end{array}$ & & & & & & & & & \\
\hline & IV & All Classes & All Classes & & All Classes & All Classes & All Classes & All Classe & & 3rd Class \\
\hline \multirow{4}{*}{1905} & 1 & All Classes & All Classes & & All Classes & All Classes & All Classes & All Classe & & 3rd Class \\
\hline & II & All Classes & All Classes & & All Classes & All Classes & All Classes & All Classe & & 3rd Class \\
\hline & III & All Classes & All Classes & & All Classes & All Classes & All Classes & All Classe & & 3rd Class \\
\hline & IV & All Classes & All Classes & & All Classes & All Classes & All Classes & All Classe & & 3rd Class \\
\hline \multirow{4}{*}{1906} & I & All Classes & All Classes & & All Classes & All Classes & All Classes & All Classe & & 3rd Class \\
\hline & II & All Classes & All Classes & & All Classes & All Classes & All Classes & All Classe & & 3rd Class \\
\hline & III & All Classes & All Classes & & All Classes & All Classes & All Classes & All Class & & 3rd Class \\
\hline & IV & All Classes & All Classes & & All Classes & All Classes & All Classes & All Classe & & 3rd Class \\
\hline \multirow{3}{*}{1907} & 1 & All Classes & All Classes & & All Classes & All Classes & All Classes & All Classe & & 3rd Class \\
\hline & II & All Classes & All Classes & & All Classes & All Classes & All Classes & All Classe & & 3rd Class \\
\hline & $\begin{array}{l}\text { III } \\
\text { IV }\end{array}$ & & & & & & & & & \\
\hline \multirow{4}{*}{1908} & 1 & All Classes & All Classes & & & All Classes & All Classes & All Classes & & \\
\hline & II & All Classes & All Classes & & & All Classes & All Classes & All Classes & & 3rd Class \\
\hline & III & All Classes & All Classes & & & All Classes & All Classes & All Classes & & 3rd Class \\
\hline & IV & All Classes & All Classes & & & All Classes & All Classes & All Classes & & 3rd Class \\
\hline \multirow{4}{*}{1909} & 1 & All Classes & All Classes & All Classes & All Classes & All Classes & All Classes & All Classes & All Classes & 3rd Class \\
\hline & II & All Classes & All Classes & All Classes & All Classes & All Classes & All Classes & All Classes & All Classes & 3rd Class \\
\hline & III & All Classes & All Classes & All Classes & All Classes & All Classes & All Classes & All Classes & All Classes & 3rd Class \\
\hline & IV & All Classes & All Classes & All Classes & All Classes & All Classes & All Classes & All Classes & All Classes & 3rd Class \\
\hline \multirow{4}{*}{1910} & I & All Classes & All Classes & All Classes & All Classes & All Classes & All Classes & All Classes & All Classes & 3rd Class \\
\hline & II & All Classes & All Classes & All Classes & All Classes & All Classes & All Classes & All Classes & All Classes & 3rd Class \\
\hline & III & All Classes & All Classes & All Classes & All Classes & All Classes & All Classes & All Classes & All Classes & 3rd Class \\
\hline & IV & All Classes & All Classes & All Classes & All Classes & All Classes & All Classes & All Classes & All Classes & 3rd Class \\
\hline & 1 & All Classes & All Classes & All Classes & All Classes & All Classes & All Classes & All Classes & All Classes & 3rd Class \\
\hline 191 & II & All Classes & All Classes & All Classes & All Classes & All Classes & All Classes & All Classes & All Classes & 3rd Class \\
\hline 1911 & III & All Classes & All Classes & All Classes & All Classes & All Classes & All Classes & All Classes & All Classes & 3rd Class \\
\hline & IV & All Classes & All Classes & All Classes & All Classes & All Classes & All Classes & All Classes & All Classes & 3rd Class \\
\hline
\end{tabular}

Notes: In the regression, quarters correspond to indicators as follows: Quarter I is Winter, Quarter II is Spring, Quarter III is Summer, and Quarter IV is Fall. Dark (turquoise) shaded areas correspond to the normal operation of a cartel. Light (grey) shaded areas correspond to disrupted cartel agreement. Unshaded areas correspond to the absence of a cartel or a price war. Striped cells indicate absence of service. Sources: see text. 
Table 2. Summary Statistics

\begin{tabular}{|c|c|c|c|c|c|c|c|}
\hline \multirow{2}{*}{$\begin{array}{l}\text { Panel A. Passenger Flows } \\
\text { Direction and class of service }\end{array}$} & \multicolumn{3}{|c|}{ All observations } & \multicolumn{2}{|c|}{ Collusive periods } & \multicolumn{2}{|c|}{ Non collusive periods } \\
\hline & Mean & Std Dev & Obs & Mean & Obs & Mean & Obs \\
\hline \multicolumn{8}{|l|}{ Westbound Flows } \\
\hline First Class & 3,817 & 4,683 & 298 & 5,129 & 135 & 2,730 & 163 \\
\hline Second Class & 6,378 & 6,945 & 318 & 8,586 & 141 & 4,619 & 177 \\
\hline Third Class & 31,876 & 32,688 & 325 & 28,258 & 178 & 36,256 & 147 \\
\hline \multicolumn{8}{|l|}{ Eastbound Flows } \\
\hline First Class & 4,025 & 4,267 & 265 & 4,728 & 132 & 3,327 & 133 \\
\hline Second Class & 4,004 & 4,285 & 258 & 4,843 & 124 & 3,226 & 134 \\
\hline Third Class & 15,333 & 18,560 & 266 & 12,240 & 163 & 20,228 & 103 \\
\hline Panel B. Economic Variables & \multirow{2}{*}{\multicolumn{5}{|c|}{ All observations in the sample (3rd class westbound) }} & \multicolumn{2}{|c|}{ Non collusive periods } \\
\hline & & & & & & (3rd class & stbound) \\
\hline Variable & Mean & Std Dev & Obs & Mean & Obs & Mean & Obs \\
\hline US Employment (index) & 84.30 & 9.94 & 325 & 85.28 & 178 & 83.11 & 147 \\
\hline US Employment (quarterly growth) & 0.72 & 2.63 & 325 & 0.98 & 178 & 0.40 & 147 \\
\hline North American GDP (index) & 75.24 & 10.94 & 325 & 75.57 & 178 & 74.85 & 147 \\
\hline European GDP (index) & 83.46 & 7.25 & 325 & 83.86 & 178 & 82.97 & 147 \\
\hline US Unemployment Rate & 4.70 & 1.61 & 325 & 5.39 & 178 & 3.86 & 147 \\
\hline North American Wage (index) & 170.29 & 12.26 & 325 & 170.21 & 178 & 170.39 & 147 \\
\hline European Wage (index) & 80.64 & 17.73 & 325 & 83.71 & 178 & 76.94 & 147 \\
\hline
\end{tabular}

Notes: Collusive periods refer to quarters with normally functioning cartels. Passenger flows are number of passengers in each quarter per route (mean and standard deviation are taken over route-quarters with positive flows). US employment is a factory employment index, with 1914=100. Quarterly employment growth is the change of this index. GDP figures are based on country-specific indexes that are equal to 100 in 1913 for all countries. The indexes are averaged based on the number of sailings and average immigration flows to yield composite area GDP indexes. Wage figures are based on country-specific real wage indexes (UK wages in 1905 $=100$ ). Constituent country indexes are weighted by the number of sailings and average immigration flows to yield the composite area wage indexes. See text for sources. 
Table 3. Passenger Flows, by Direction of Travel and Class of Service: Economic growth controls

\begin{tabular}{|c|c|c|c|c|c|c|}
\hline & \multicolumn{3}{|c|}{ Westbound } & \multicolumn{3}{|c|}{ Eastbound } \\
\hline & First Class & Second Class & Third Class & First Class & Second Class & Third Class \\
\hline \multirow[t]{2}{*}{$\overline{\text { Constant }}$} & 3.857 & 4.718 & 7.342 & 3.731 & 4.069 & 5.789 \\
\hline & 0.081 & 0.056 & 0.088 & 0.099 & 0.083 & 0.134 \\
\hline \multirow[t]{2}{*}{ Cartel Agreement } & 0.082 & 0.194 & -0.018 & -0.041 & 0.027 & -0.165 \\
\hline & 0.050 & 0.067 & 0.071 & 0.085 & 0.068 & 0.129 \\
\hline \multirow[t]{2}{*}{ Normal Cartel Operation } & -0.106 & -0.195 & -0.323 & -0.084 & -0.169 & -0.344 \\
\hline & 0.039 & 0.047 & 0.040 & 0.063 & 0.056 & 0.070 \\
\hline \multirow[t]{2}{*}{ Factory Employment } & 0.001 & 0.003 & 0.017 & 0.012 & 0.006 & -0.006 \\
\hline & 0.006 & 0.009 & 0.011 & 0.011 & 0.010 & 0.014 \\
\hline \multirow[t]{2}{*}{ Destination GDP } & 0.013 & 0.003 & 0.026 & -0.005 & -0.016 & 0.009 \\
\hline & 0.006 & 0.006 & 0.007 & 0.015 & 0.013 & 0.018 \\
\hline \multirow[t]{2}{*}{ Origin GDP } & -0.004 & -0.022 & -0.017 & 0.015 & 0.016 & 0.025 \\
\hline & 0.010 & 0.011 & 0.010 & 0.010 & 0.008 & 0.012 \\
\hline \multirow[t]{2}{*}{ Year 1908} & -0.002 & -0.122 & -0.685 & 0.059 & 0.167 & 0.369 \\
\hline & 0.063 & 0.090 & 0.135 & 0.133 & 0.099 & 0.189 \\
\hline \multirow[t]{2}{*}{ Quarterly Trend } & 0.015 & 0.035 & 0.018 & 0.012 & 0.026 & 0.033 \\
\hline & 0.001 & 0.001 & 0.001 & 0.001 & 0.002 & 0.002 \\
\hline \multirow[t]{2}{*}{ Spring } & 0.719 & 0.579 & 0.719 & 1.346 & 1.394 & 0.985 \\
\hline & 0.041 & 0.048 & 0.054 & 0.067 & 0.068 & 0.084 \\
\hline \multirow[t]{2}{*}{ Summer } & 1.579 & 0.665 & 0.221 & 0.964 & 1.101 & 0.870 \\
\hline & 0.041 & 0.044 & 0.051 & 0.070 & 0.066 & 0.077 \\
\hline \multirow[t]{2}{*}{ Fall } & 0.970 & 0.487 & 0.118 & 0.254 & 0.613 & 0.976 \\
\hline & 0.040 & 0.049 & 0.045 & 0.053 & 0.070 & 0.075 \\
\hline \multirow[t]{2}{*}{ USA-Britain } & 3.955 & 3.229 & 2.652 & 4.381 & 3.281 & 2.550 \\
\hline & 0.088 & 0.087 & 0.058 & 0.102 & 0.072 & 0.082 \\
\hline \multirow[t]{2}{*}{ USA-Mediterranean } & 2.520 & 1.537 & 2.827 & 3.529 & 1.828 & 2.900 \\
\hline & 0.093 & 0.102 & 0.073 & 0.114 & 0.083 & 0.090 \\
\hline \multirow[t]{2}{*}{ USA-North France } & 1.762 & 1.304 & 1.344 & 0.451 & 1.347 & 0.157 \\
\hline & 0.088 & 0.071 & 0.060 & 0.452 & 0.118 & 0.550 \\
\hline \multirow[t]{2}{*}{ USA-Rhine } & 3.654 & 3.202 & 3.319 & 4.031 & 3.139 & 2.864 \\
\hline & 0.079 & 0.068 & 0.065 & 0.099 & 0.074 & 0.079 \\
\hline \multirow[t]{2}{*}{ Canada-Britain } & 2.175 & 2.548 & 1.830 & 2.471 & 2.131 & 1.143 \\
\hline & 0.085 & 0.080 & 0.066 & 0.104 & 0.074 & 0.093 \\
\hline \multirow[t]{2}{*}{ Canada-Rhine } & -3.050 & -2.563 & 0.135 & na & na & na \\
\hline & 1.271 & 0.116 & 0.107 & na & na & na \\
\hline \multirow{2}{*}{$\begin{array}{l}\text { Memo: Total Effect of } \\
\text { Normally Operating Cartel }\end{array}$} & -0.024 & 0.000 & -0.341 & -0.125 & -0.142 & -0.509 \\
\hline & 0.042 & 0.065 & 0.064 & 0.057 & 0.062 & 0.113 \\
\hline \multirow{2}{*}{$\begin{array}{l}\text { R-squared (unweighted) } \\
\text { R-squared (weiahted) }\end{array}$} & 0.9277 & 0.9368 & 0.9173 & 0.8245 & 0.8823 & 0.7437 \\
\hline & 0.9591 & 0.9693 & 0.9418 & 0.9415 & 0.9566 & 0.9138 \\
\hline
\end{tabular}

Notes: (i) Standard errors are reported in italics, underneath the parameter estimates. (ii) The omitted route dummy variable is USAScandinavia. (iii) The number of observations westbound is 298 for first class, 318 for second class and 325 for third class. The number of observations eastbound is 265 for first class, 258 for second class and 266 for third class. (iv) Factory employment is in first differences of the relevant index. (v) Destination and origin GDP are deviations from trend of the relevant indexes. (vi) Weighted Rsquared weighs observations using GLS weights. See text for details on variable construction. 
Table 4. Passenger Flows, by Direction of Travel and Class of Service: Labor Market Economic controls

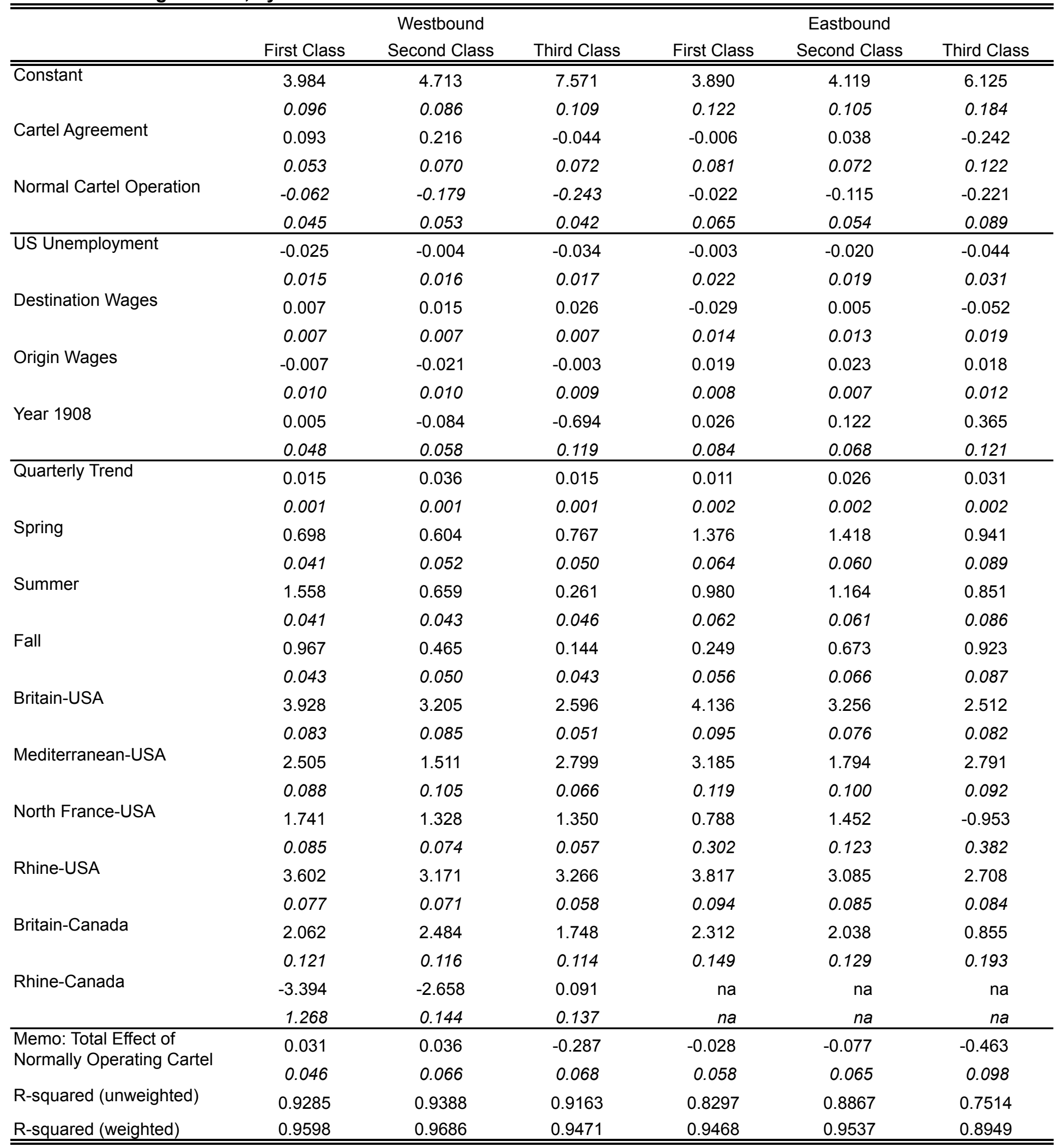

Notes: (i) Standard errors are reported in italics, underneath the parameter estimates. (ii) The omitted route dummy variable is USAScandinavia. (iii) The number of observations for the wesbound regressions is 298 for first class, 318 for second class and 325 for third class. The number of observations for eastbound regression is 265 for first class, 258 for second class and 266 for third class. (iv) US Unemployment applies to routes to/from the US. (v) Destination and origin wages are deviations from trend for the relevant indexes. (vi) Weighted R-squared weighs observations using GLS weights. See text for details on variable construction. 
Table 5. Passenger Flows, by Direction of Travel and Class of Service: High Order Economic controls

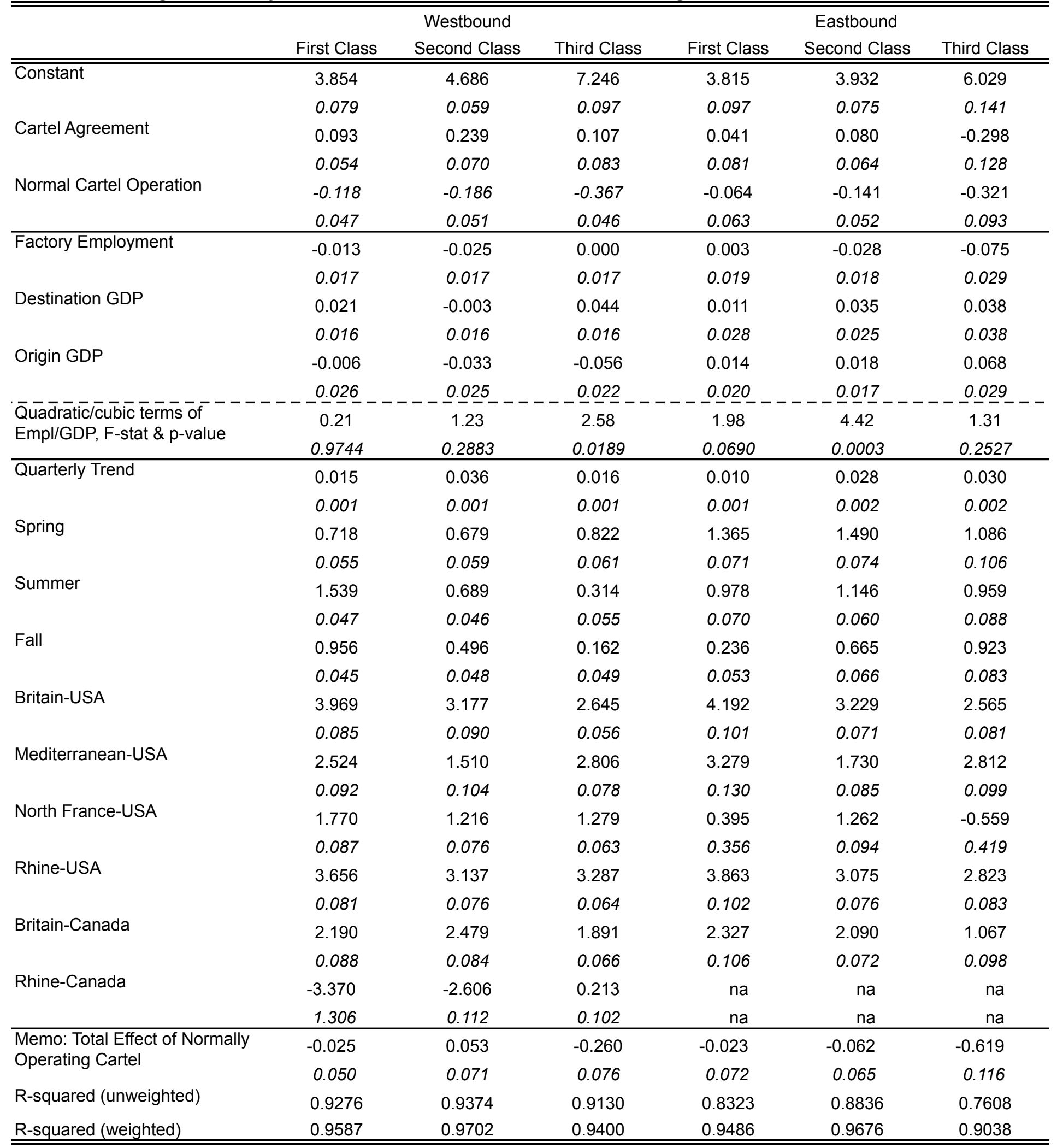

Notes: (i) Standard errors are reported in italics, underneath the parameter estimates. (ii) The omitted route dummy variable is USAScandinavia. (iii) The number of observations for the wesbound regressions is 298 for first class, 318 for second class and 325 for third class. The number of observations for eastbound regression is 265 for first class, 258 for second class and 266 for third class. (iv) Factory employment is in first differences of the relevant index. (v) Destination and origin gdp are deviations from trend of the relevant indexes. (vi) Weighted R-squared weighs observations using GLS weights. See text for details on variable construction. 
Table 6. Collusion Effects on Westbound Fares by Class of Service

\begin{tabular}{|c|c|c|c|c|c|c|}
\hline \multirow[b]{2}{*}{ Constant } & \multicolumn{2}{|c|}{$\begin{array}{l}\text { Third Class Annual Data } \\
\text { multiple ports/firms }\end{array}$} & \multicolumn{2}{|c|}{$\begin{array}{l}\text { Third Class Quarterly Data } \\
\text { Liverpool/Rotterdam }\end{array}$} & \multicolumn{2}{|c|}{$\begin{array}{l}\text { Cabin Class Quarterly Data } \\
\text { Liverpool/Rotterdam }\end{array}$} \\
\hline & 3.329 & 3.330 & 3.337 & 3.336 & 3.510 & 3.510 \\
\hline \multirow{3}{*}{ Normal Cartel Agreement } & 0.043 & 0.043 & 0.050 & 0.047 & 0.043 & 0.042 \\
\hline & 0.132 & 0.133 & 0.219 & 0.272 & 0.166 & 0.182 \\
\hline & 0.037 & 0.038 & 0.049 & 0.047 & 0.025 & 0.027 \\
\hline \multirow[t]{2}{*}{ First Class } & - & - & - & - & 0.746 & 0.746 \\
\hline & - & - & - & - & 0.026 & 0.026 \\
\hline \multirow[t]{2}{*}{ Year 1908} & - & -0.012 & & -0.250 & - & -0.076 \\
\hline & - & 0.038 & & 0.053 & - & 0.048 \\
\hline \multirow[t]{2}{*}{ Spring } & - & - & 0.076 & 0.076 & 0.121 & 0.121 \\
\hline & - & - & 0.058 & 0.048 & 0.041 & 0.041 \\
\hline \multirow[t]{2}{*}{ Summer } & - & - & 0.041 & 0.041 & 0.204 & 0.204 \\
\hline & - & - & 0.074 & 0.069 & 0.040 & 0.040 \\
\hline \multirow[t]{2}{*}{ Fall } & - & - & 0.077 & 0.083 & 0.200 & 0.202 \\
\hline & - & - & 0.068 & 0.064 & 0.039 & 0.038 \\
\hline \multirow[t]{2}{*}{ Liverpool (Cunard) } & -0.327 & -0.327 & -0.477 & -0.477 & 0.159 & 0.159 \\
\hline & 0.073 & 0.073 & 0.049 & 0.046 & 0.026 & 0.026 \\
\hline \multirow[t]{2}{*}{ Glasgow (Anchor) } & -0.278 & -0.277 & - & - & - & - \\
\hline & 0.060 & 0.060 & - & - & - & - \\
\hline \multirow[t]{2}{*}{ Mediterranean (Cunard) } & -0.143 & -0.142 & - & - & - & - \\
\hline & 0.048 & 0.048 & - & - & - & - \\
\hline \multirow[t]{2}{*}{ Italy (official and corporate docs) } & 0.106 & 0.107 & - & - & - & - \\
\hline & 0.041 & 0.041 & - & - & - & - \\
\hline \multirow{2}{*}{$\begin{array}{l}\text { Germany (Hamburg American } \\
\text { and North German Lloyd) }\end{array}$} & 0.104 & 0.104 & - & - & - & - \\
\hline & 0.048 & 0.048 & - & - & - & - \\
\hline \multirow[t]{2}{*}{ Oslo (official docs) } & -0.047 & -0.047 & - & - & - & - \\
\hline & 0.067 & 0.068 & - & - & - & - \\
\hline R-squared & 0.6406 & 0.6409 & 0.6390 & 0.6894 & 0.8737 & 0.8765 \\
\hline Observations & 66 & 66 & 72 & 72 & 144 & 144 \\
\hline
\end{tabular}

Notes: The dependent variable is the natural log of the fare in US dollars, adjusted for inflation. The first two columns cover the period of 1901 to 1911, but some routes cover a sub-set of that period. The last two columns cover the period 1903 to 1911. Robust standard errors are reported in italics below the parameter estimates. The name of the shipping line from which the data is based is reported next to the port name in parenthesis. Rotterdam (Holland America) is the ommitted route for all regressions. Data obtained from multiple sources. See text for details. 
Table 7. Collusion-Induced Cabin Class Substitution, Excluding Routes from Scandinavia

\begin{tabular}{|c|c|c|c|c|c|}
\hline \multirow{3}{*}{$\begin{array}{l}\text { Cabin class under } \\
\text { counterfactual of } \\
\text { no collusive agreement }\end{array}$} & \multicolumn{5}{|c|}{ Passenger flows for typical route-quarter under collusive status } \\
\hline & \multicolumn{5}{|c|}{ Westbound flows with normally functioning collusion } \\
\hline & First Class & Second Class & Third Class & Displaced & Total \\
\hline First Class & 4,763 & 113 & & & 4,877 \\
\hline Second Class & & 8,059 & 117 & & 8,175 \\
\hline Third Class & & & 33,181 & 13,635 & 46,815 \\
\hline Total & 4,763 & 8,172 & 33,297 & 13,635 & \\
\hline \multirow[t]{3}{*}{ Quarters with passengers } & 139 & 145 & 151 & na & \\
\hline & \multicolumn{5}{|c|}{ Eastbound flows with normally functioning collusion } \\
\hline & First Class & Second Class & Third Class & Displaced & Total \\
\hline First Class & 4,727 & 629 & & & 5,357 \\
\hline Second Class & & 4,177 & 1,365 & & 5,541 \\
\hline Third Class & & & 13,185 & 11,027 & 24,212 \\
\hline Total & 4,727 & 4,806 & 14,550 & 11,027 & \\
\hline Quarters with passengers & 136 & 128 & 136 & na & \\
\hline
\end{tabular}

Notes. Numbers may not add up because of independent rounding of counterfactual figures. The averaging of total flows is over the number of periods with positive steerage flows. See text for details. 
Table 8. Quantitative Analysis: Inputs and Results

\begin{tabular}{|c|c|c|c|c|c|c|}
\hline \multicolumn{2}{|c|}{ Passenger Volume per Quarter-Route } & \multicolumn{2}{|l|}{ Westbound } & \multicolumn{3}{|c|}{ Eastbound } \\
\hline & First Class & Second Class & Third Class & First Class & Second Class & Third Class \\
\hline Collusive Regime & 4,763 & 8,172 & 33,297 & 4,727 & 4,806 & 14,550 \\
\hline Competitive Counterfactual & 4,877 & 8,175 & 46,815 & 5,357 & 5,541 & 24,212 \\
\hline Cartel Effect & $-2 \%$ & $0 \%$ & $-29 \%$ & $-12 \%$ & $-13 \%$ & $-40 \%$ \\
\hline \multirow[t]{2}{*}{ Actual Prices } & \multicolumn{3}{|c|}{ Westbound } & \multicolumn{3}{|c|}{ Eastbound } \\
\hline & First Class & Second Class & Third Class & First Class & Second Class & Third Class \\
\hline Collusive Regime & $\$ 111.70$ & $\$ 47.81$ & $\$ 32.41$ & $\$ 85.90$ & $\$ 45.32$ & $\$ 33.31$ \\
\hline Competitive Regime & $\$ 86.27$ & $\$ 43.01$ & $\$ 24.70$ & $\$ 61.33$ & $\$ 36.89$ & $\$ 21.05$ \\
\hline Cartel Effect & $29 \%$ & $11 \%$ & $31 \%$ & $40 \%$ & $23 \%$ & $58 \%$ \\
\hline \multirow[t]{2}{*}{ Parameter Estimates } & \multicolumn{2}{|c|}{ First Class } & \multicolumn{2}{|c|}{ Second Class } & Steerage & Market Size \\
\hline & Collusive & Competitive & Collusive & Competitive & & \\
\hline Westbound & 143.1 & 124.9 & 76.2 & 79.5 & 58.6 & 103,500 \\
\hline Eastbound & 119.1 & 107.1 & 74.7 & 79.9 & 60.1 & 54,050 \\
\hline \multirow[t]{2}{*}{ Prices Predicted by the Model } & \multicolumn{3}{|c|}{ Westbound } & \multicolumn{3}{|c|}{ Eastbound } \\
\hline & First Class & Second Class & Third Class & First Class & Second Class & Third Class \\
\hline Collusive Regime & 111.24 & 57.74 & 39.43 & 90.23 & 55.78 & 40.57 \\
\hline Cartel Effect & $29 \%$ & $34 \%$ & $60 \%$ & $47 \%$ & $51 \%$ & $93 \%$ \\
\hline
\end{tabular}

Notes: See text for details. 
Table 9. Cartelization and Immigrant Selection

\begin{tabular}{lccccc} 
& Model 1 & Model 2 & Model 3 & Model 4 & Model 5 \\
\hline \hline Panel A: Illiteracy Rates & & & & & \\
Constant & na & na & na & 27.69 & 26.30 \\
& $n a$ & $n a$ & $n a$ & 3.89 & 1.28 \\
Normal Cartel Operartion & -1.29 & -1.64 & -1.31 & -12.98 & -9.32 \\
& 0.55 & 0.62 & 0.52 & 3.03 & 2.10 \\
Annual Trend & 0.05 & 0.89 & 0.06 & 0.30 & - \\
& 0.08 & 1.05 & 0.08 & 0.46 & - \\
Year 1908 & 0.15 & 0.89 & - & -4.03 & - \\
& 1.12 & 1.05 & - & 6.67 & - \\
Ethnicity Fixed Effects & Yes & Yes & Yes & No & No \\
Ethnicity Weighted Regression & Yes & No & Yes & Yes & No \\
R-squared & 0.9740 & 0.9375 & 0.9740 & 0.0755 & 0.0400 \\
& & & & & \\
\hline Panel B: Average Money & & & & & \\
Constant & na & na & na & 19.85 & 34.38 \\
& $n a$ & $n a$ & $n a$ & 2.78 & 1.34 \\
Normal Cartel Operartion & 2.25 & 1.46 & 2.78 & 7.25 & 4.64 \\
& 1.32 & 1.27 & 1.28 & 3.30 & 2.84 \\
Annual Trend & 1.33 & 1.27 & 1.26 & 1.22 & - \\
Year 1908 & 0.15 & 0.15 & 0.14 & 0.38 & - \\
& -3.58 & -4.87 & - & -1.79 & - \\
Ethnicity Fixed Effects & 0.94 & 1.40 & - & 4.86 & - \\
Ethnicity Weighted Regression & Yes & Yes & Yes & No & No \\
R-squared & 0.9006 & 0.7863 & 0.8987 & 0.0839 & 0.0079 \\
\hline \hline
\end{tabular}

Notes. Annual Trend: $1899=1$. Illiteracy rates are in percentage points $(0-100)$. Average money is in current dollars per (reporting) immigrant. Ethnicity weights are proportional to the total number of immigrants of that ethnicity over the sample period. Robust standard errors are reported in italics below the parameter estimates. See text for further discussion and detais. $\mathrm{N}=377$. 

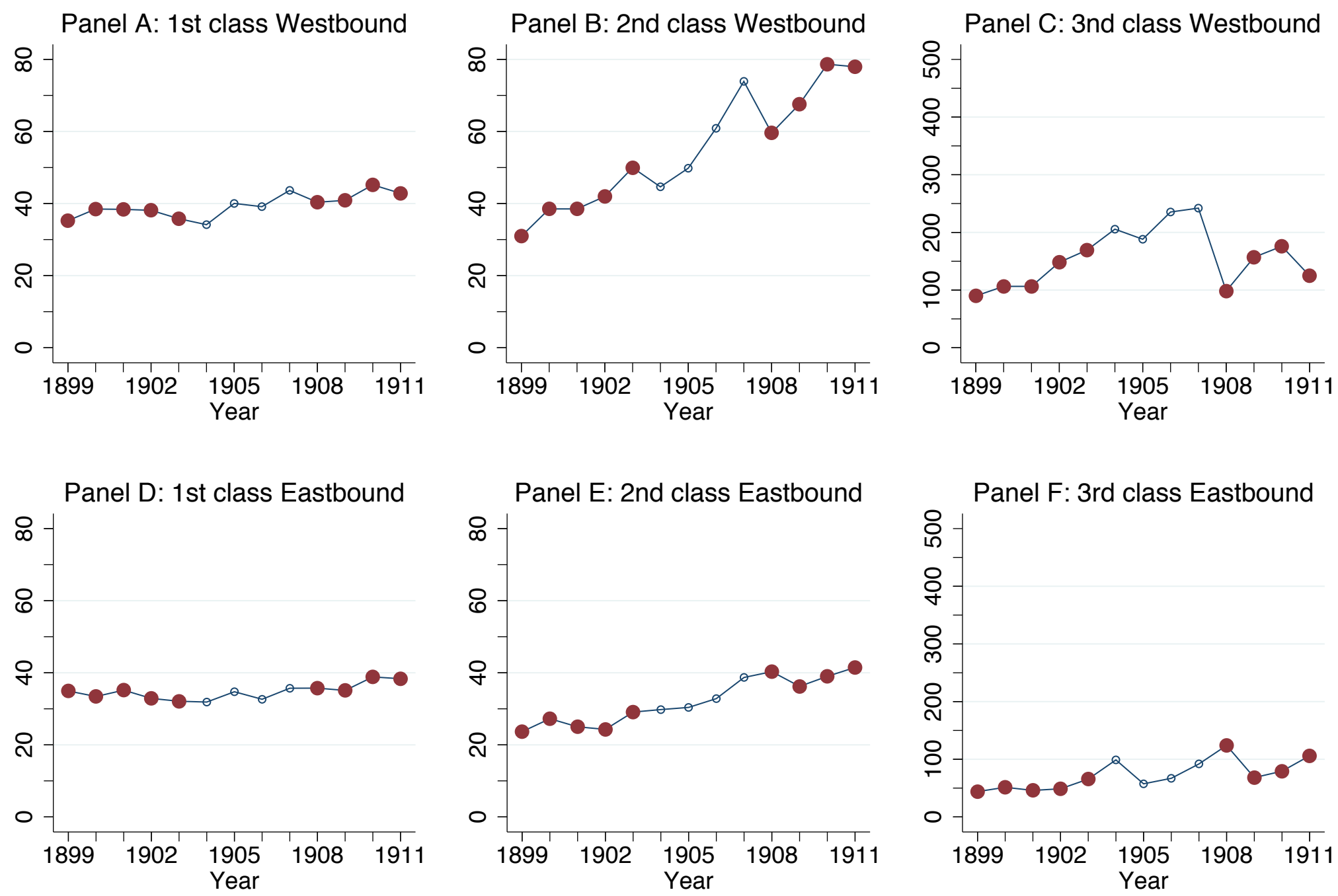

Figure 1 

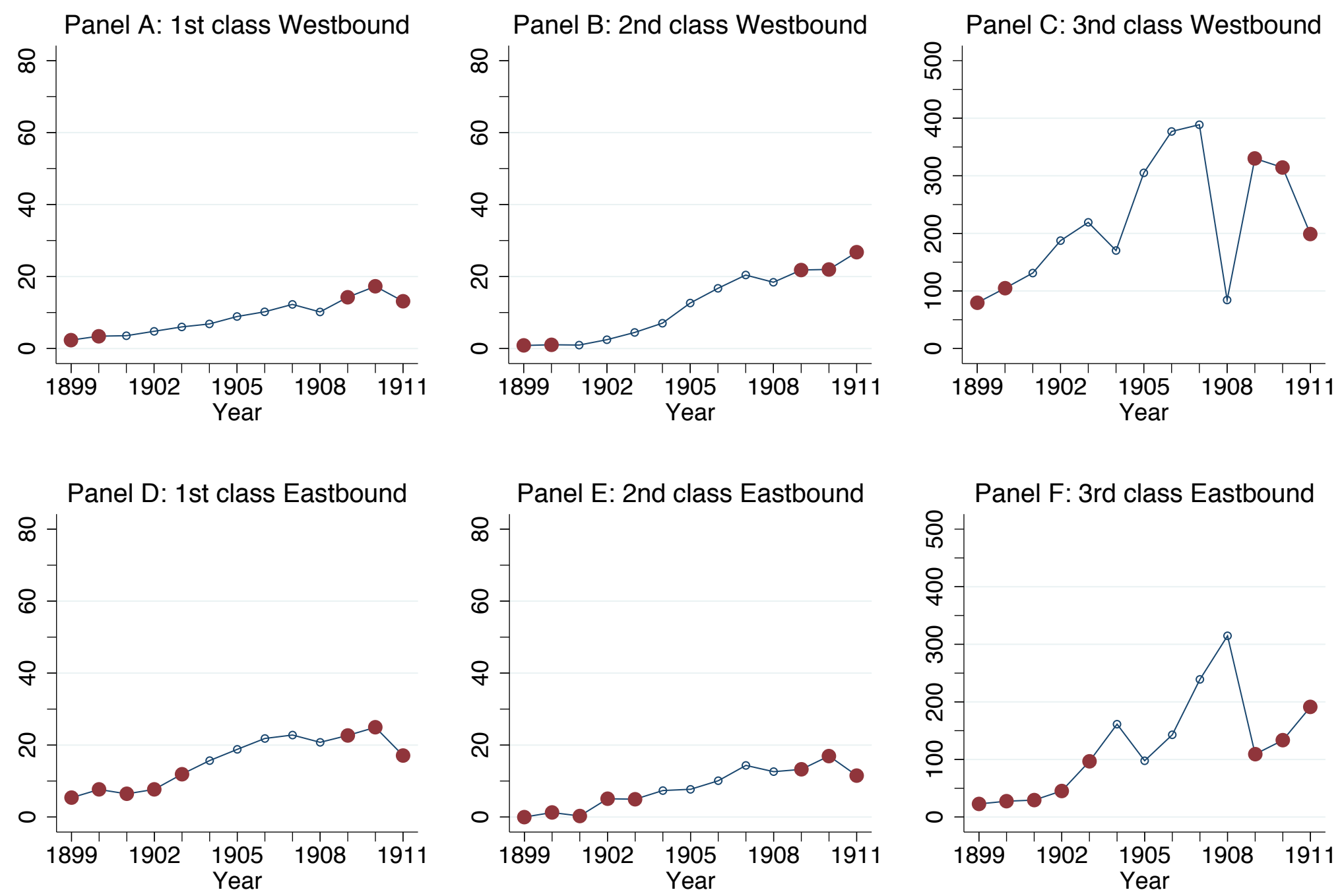

Figure 2 

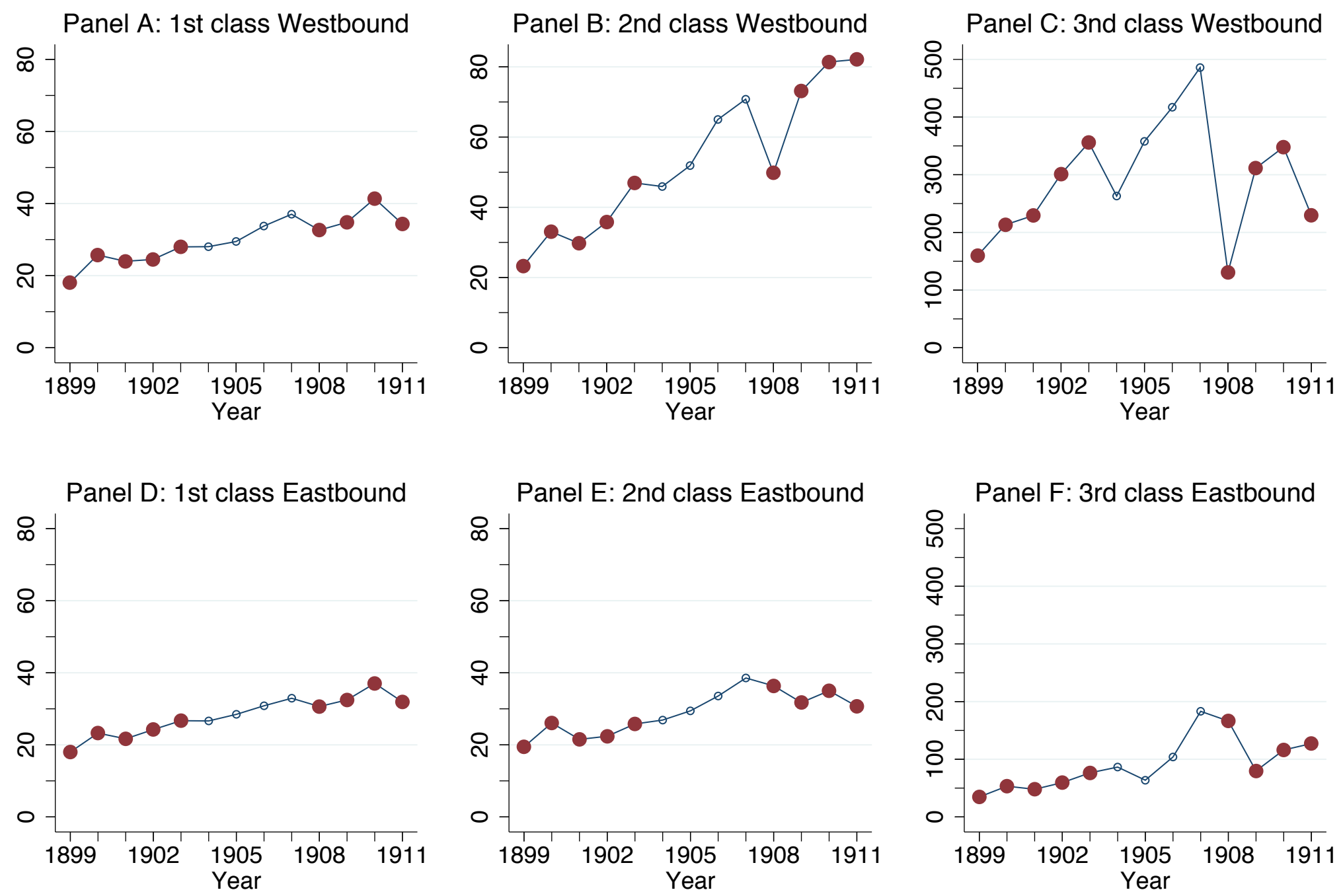

Figure 3 